\title{
Quality Saúde - uma adaptação transcultural multicêntrica dos constructos da escala Servqual de satisfação para o SUS,
por translação de conhecimento
de especialistas e usuários
}

\author{
Galba Freire Moita \\ Ministério da Saúde e da Fundação Osvaldo Cruz
}

Allan Claudius Queiroz Barbosa

Universidade Federal de Minas Gerais (UFMG)

Vitor Manuel Reis Raposo

Universidade de Coimbra, Portugal

O Conselho Federal de Medicina $(2014,2015)$ publicou pesquisas que revelaram uma suposta insatisfação de mais de $90 \%$ da população brasileira no que diz respeito à saúde pública e à suplementar. Em uma pesquisa bibliográfica integrativa sobre a mensuração de qualidade e satisfação do usuário de saúde no Brasil são tímidos os resultados obtidos, além de não haver registros de padronização de sistemas de mensuração de qualidade e satisfação no SUS. Por sua vez, uma breve análise da escala proposta na iniciativa do Gespública (BRASIL, 2014) revela muita similaridade com as cinco dimensões e com as 22 questões da escala original Servqual (PARASURAMAN et al., 1991a ; BERRY et al., 1994), mas, não há evidências da validade na construção da escala de satisfação que compõe o IPPS. Objetivo: estudaram-se as questões da escala Servqual visando à validação de constructos (ideiasforças) representativos das 22 questões originais, no âmbito do SUS. Métodos: Os resultados obtidos das respostas de 195 profissionais e 506 usuários, em três fases sucessivas (painel de especialistas, grupos Delphi e pesquisa de campo), foram objetos de análise descritiva e de significância estatística. Resultados/conclusões: os 40 constructos, 22 subdimensões e 05 macrodimensões que surgiram e tiveram valorações médias acima do nível 3 (relevante) foram usados para análise inferencial, com rigor metodológico. As análises de confiabilidade e validade resultaram em um modelo final de 38 constructos, 15 subdimensões e quatro macrodimensões que podem, futuramente, basear a proposição de questões pertinentes em um instrumento avaliativo de qualidade percebida (satisfação) no SUS.

Palavras-Chave: qualidade de saúde, saúde pública, pesquisa de satisfação do cliente, pesquisa qualitativa, Sistema Único de Saúde, Brasil

[Artigo recebido em 30 de novembro de 2017. Aprovado em 27 de fevereiro de 2019.] 


\section{Quality Saúde - una adaptación transcultural multicéntrica de los constructos de la escala Servqual de satisfacción para el SUS, por traslación de conocimiento de especialistas y usuarios}

El Consejo Federal de Medicina $(2014,2015)$ publicó investigaciones que revelaron una supuesta insatisfacción de cerca del $87 \%$ con la salud brasileña. En una investigación bibliográfica integrativa sobre medición de calidad y satisfacción del usuario son tímidos los resultados obtenidos. No hay registros de estandarización de sistemas de medición de calidad y satisfacción en el SUS. Un breve análisis de la escala propuesta en la iniciativa del Gespública (BRASIL, 2014) revela mucha similitud con las cinco dimensiones y con las 22 cuestiones de la escala original Servqual (PARASURAMAN et al., 1991a; BERRY et al., 1994), pero aparentemente, en la composición de la escala de satisfacción que compone el IPPS. Objetivo: se estudiaron las cuestiones de la escala Servqual con el objetivo de validar las construcciones (ideas-fuerzas) representativas de los 22 temas originales dentro deISUS. Métodos: los resultados obtenidos de las respuestas de 195 profesionales y 506 usuarios, en tres fases sucesivas (panel de expertos, grupos Delphi y estudio de campo), fueron objetos de análisis descriptivo y de significancia estadística. Resultados/conclusiones: los 40 constructos, 22 subdimensiones y 5 macrodimensiones que surgieron y tuvieron valoraciones medias por encima del nivel 3 (relevante) fueron usadas para análisis inferencial, con rigor metodológico. Los análisis de confiabilidad y validez resultaron en un modelo final de 38 constructos, 15 subdimensiones y cuatro macrodimensiones que pueden, en el futuro, basar la proposición de cuestiones pertinentes en un instrumento de evaluación de calidad percibida (satisfacción) en el SUS.

Palabras clave: calidad de salud, salud pública, investigación de satisfacción del cliente, investigación cualitativa, Sistema Único de Saúde, Brasil

\section{Quality Saúde - a multi-centric cross-cultural adaptation of the Servqual satisfaction constructs for the SUS, by translating knowledge from experts and users}

The Federal Council of Medicine $(2014,2015)$ published research that revealed an alleged dissatisfaction of more than $87 \%$ of the Brazilian population with regard to public health and supplementary health. In an integrative bibliographical research on the measurement of quality and satisfaction of the health user in Brazil, the results obtained are timid, besides there are no records of standardization of quality measurement and satisfaction systems in SUS. In turn, a brief analysis of the scale proposed in the Gespública initiative (BRASIL, 2014) reveals much similarity with the five dimensions and with the 22 questions of the original Servqual scale (PARASURAMAN et al., 1991a; BERRY et al., 1994), but there is no evidence of the validity in the construction of the satisfaction scale that makes up the IPPS. Objective: The questions of the Servqual scale were studied aiming at the validation of constructs (ideasforces) representative of the 22 original issues within the SUS. Methods: The results obtained from the replies of 195 professionals and 506 users, in three successive phases (expert panel, Delphi groups and field survey), were objects of descriptive analysis and of statistical significance. Results/conclusions: the 40 constructs, 22 subdimensions and 05 (macro) dimensions emerged and had mean values above level 3 (relevant) were used for inferential analysis with methodological rigor. The reliability and validity analyze resulted in a final model of 38 constructs, 15 subdimensions and four macro dimensions that may, in the future, base the proposition of pertinent questions on a perceptual quality instrument (satisfaction) in SUS.

Keywords: quality of health, public health, customer satisfaction research, qualitative research, Sistema Único de Saúde, Brazil 


\section{Introdução}

As bases da avaliação de qualidade e dos estudos econômicos em saúde foram lançadas antes da década de 1970, mas a maioria dos estudos apontam Avedis Donabedian como debatedor seminal sobre a estruturação do sistema de avaliação em serviços de saúde, que, em 1980, a partir da teoria dos sistemas organizacionais, apresentou uma proposta de avaliação pautada em três pilares: estrutura, processos e resultados, com o objetivo de aferir o desempenho e os resultados de serviços de saúde. Escorel et al. (2007) afirmam que os serviços de saúde precisam ser constantemente monitorados e avaliados, como forma de garantir a qualidade do atendimento.

Nesse propósito, a avaliação de qualidade e satisfação no âmbito da oferta de serviços tem sido um desafio para acadêmicos e gestores. Em 2014 e 2015, o Conselho Federal de Medicina publicou pesquisas que revelaram uma suposta insatisfação de mais de $87 \%$ da população brasileira no que diz respeito à saúde pública e à suplementar. Nesse cenário, evidencia-se a importância de se avaliar a satisfação relatada por usuários de saúde. Entretanto, a pesquisa integrativa realizada revela que no Brasil são tímidas as iniciativas de avaliação de qualidade e satisfação através de instrumentos padronizados e devidamente validados.

Em busca de desenvolver um método de mensuração da satisfação de usuários de serviços públicos, um estudo do Ministério do Planejamento do Brasil propôs a criação do Instrumento Padrão de Pesquisa e Satisfação (IPPS) tendo analisado três metodologias internacionais (o American Consumer Satisfaction Index da Universidade de Michigan; o Servqual - dos especialistas Zeithaml, Parasuraman e Berry- e também do Common Measurement Tool do Centro Canadense de Gestão), no âmbito do Programa Nacional da Gestão Pública e Desburocratização - Gespública (BRASIL, 2010). Destaca-se que as cinco dimensões propostas na escala Servqual (confiabilidade, capacidade de resposta, segurança, empatia e tangibilidade) e as 22 questões originais foram adaptadas e incorporadas a uma proposta de questionário do instrumento padrão de pesquisa de satisfação (IPPS) (BRASIL, 2014).

O programa Gespública foi instituído pelo Decreto n 5.378/2005 (BRASIL, 2005), e disponibiliza em seu sítio (www.gespublica.gov.br) a metodologia para elaboração da carta de serviço ao cidadão e o IPPS. Segundo Batista e Paiva (2014) o IPPS é um software que combina, na forma de um questionário de pesquisa de opinião padronizado, elementos das principais metodologias internacionais de medição de satisfação dos usuários.

No escopo da saúde, uma ampla revisão da literatura mundial aponta que a satisfação do usuário é multifacetada e de difícil mensuração (ESPERIDIÃo; 
TRAD, 2005; ESPERIDIÃO, 2009) e, assim, em muitas pesquisas surgem resultados desconectados da realidade, ou seja, existem insatisfações dos pacientes com os serviços recebidos, porém pouco explicadas nos resultados das pesquisas, possivelmente por falhas nas metodologias de mensuração, sendo um campo de interesse para os decisores de saúde (AHARONY; STRASSER, 1993 apud ESPERIDIÃO; TRAD, 2005, p. 304).

Apesar do relativo consenso de que a qualidade é vista como um dos aspectos centrais a ser considerado para a avaliação em saúde (DONABEDIAN, 1980; VuoRI, 1982), não existe uma definição universalmente aceita de cuidado em saúde, qualidade ou qualidade de atendimento. Podem-se destacar alguns estudos que apontam diferentes abordagens. Groönroos (2003) sugere mensurar a qualidade de serviços sob a ótica de seis critérios de qualidade percebida. Szymanski e Henard (2001) salientam que as investigações sobre satisfação de consumidores focam predominantemente os efeitos sobre a satisfação por meio das variáveis preditoras. Outros autores apresentam estudos aplicados com outras perspectivas e instrumentos relatados na literatura (CRONIN; TAYLOR, 1992; FERREIRA, 1993; Ferreira; RAposo, 2006; Pedro et al., 2010; Chahal; Kumari, 2011; 2012; FERREIRA et al., 2017). Neste estudo resolveu-se adotar a aferição da qualidade e satisfação pela discrepância entre expectativa (pré-consumo) e desempenho percebido (pós-consumo) defendida por outros autores (OLIVER, 1980; 1981a; b; PARASURAMAN et al., 1985b; 1988; TSE; WILTON, 1988; YI, 1990; PARASURAMAN et al., 1991b; a; PARASURAMAN et al., 1994), fundamentados no campo da translação de conhecimentos no qual as teorias consolidadas são alvos de transliteração à luz de experiências dos atores sociais envolvidos (HARTZ; JOHN, 2008; CLAVIER et al., 2011; BARBosa; Neto, 2017).

Em uma pesquisa sistemática nas principais bases de artigos científicos do Brasil, ficou patente a escassez de instrumentos de mensuração de qualidade/satisfação de usuários, pois não se identificou nenhuma metodologia robusta de avaliação de qualidade e satisfação na saúde do Brasil, achados alinhados com os resultados de uma revisão sistemática extensiva, entre 1990 e 2013, relatados por Volpato (Luciana Fernandes Volpato, 2014)(2014). Dessa forma, tem-se a questão central deste estudo: em um ambiente de escassez de metodologias e instrumentos validados e padronizados para mensuração de qualidade e satisfação na perspectiva de usuários de saúde pública, qual a importância relativa entre constructos, subdimensões e macrodimensões e seus possíveis fatores mediadores na adaptação de uma escala usada internacionalmente aplicada em saúde pública no Brasil?

Nesse contexto, surge o objetivo principal de, a partir de um modelo relevante na literatura mundial, validar e consolidar um grupo de constructos (ideias-forças) 
de qualidade/satisfação, distribuídos em subescalas de análise (subdimensões e macrodimensões) por uma amostra de profissionais e usuários de saúde pública, através de um processo de adequação, tradução transcultural e análises de confiabilidade e validade (por meio de correlação e análise fatorial exploratória), que permitam futuramente a estruturação de instrumento com questões de avaliação de qualidade/satisfação do SUS.

Assim, no âmbito do Sistema Único de Saúde (SUS), justifica-se a análise da contribuição de uma adaptação transcultural da escala Service Quality Servqual, elaborada por Parasuraman et al. (1985a), que é pautada no modelo gap model de satisfação de Oliver (1980), que afirma que a satisfação do cliente é uma função da diferença entre expectativa e desempenho, apesar de possíveis limitações relatadas na literatura (CRONIN; TAYLOR, 1992; CHAHAL; KUMARI, 2011; 2012), além da concepção de outros instrumentos (FERREIRA, 1993; FERREIRA; Mendes, 1997; Ferreira et al., 2001; Ferreira; Raposo, 2006; Pedro et al., 2010; FERREIRA et al., 2017).

Dessa forma, a proposta de tradução e adaptação transcultural da escala Servqual em um novo instrumento (Quality Saúde) fundamenta-se no campo da translação de conhecimentos no qual as teorias consolidadas são alvos de transliteração à luz de experiências dos atores sociais envolvidos (BARBOSA; NETO, 2017 apud CLAVIER et al, 2011; HARTZ et al, 2008). No presente estudo, pautouse em um processo colaborativo visando estabelecer os constructos (ideais-forças) para sintetizar e aplicar conhecimentos visando à melhoria de serviços em prol de preenchimentos de lacunas de saberes e instrumentos para transformar políticas e práticas (BARBOSA; NETO, 2017 apud CIHR, 2004, p. 2; WHO, 2006, p. 1) para a gestão de serviços do SUS. O processo aplicado pode ser expandido para outros serviços públicos, visando estruturar e validar escalas de qualidade específicas.

\section{A avaliação de qualidade e satisfação no SUS}

Quanto à medição de satisfação do usuário-utilizador de saúde, há uma histórica escassez de instrumentos no Brasil, exceto algumas experiências isoladas de organizações de saúde, que apresentam dificuldades de comparação entre unidades de saúde. Duas tentativas iniciais foram implantadas em 1998 e 2004, por uma parceria entre o MS e o Conselho Nacional de Secretários de Saúde (Conass), mas os resultados foram divulgados apenas por grandes regiões e não por unidades locais de saúde, não tendo se transformado em uma ferramenta de governação de organizações de saúde (BRASIL, 2003). Duas outras iniciativas seminais foram as chamadas pesquisa mundial de saúde (PMS), aplicada em unidades de saúde de todo o Brasil, em 2003, além da pesquisa mundial de saúde com foco na atenção 
básica (PMS-AB), aplicada somente nos estados (províncias) do Rio de Janeiro e de Pernambuco, em 2005. Ambas não tiveram continuidade e nem resultados sistematizados no sistema SUS (GouvEIA et al., 2009).

$\mathrm{Na}$ realidade do Brasil, identificaram-se duas pesquisas de opinião de base nacional do Conselho Federal de Medicina (CFM) (2014, 2015; 2018) e da Confederação Nacional da Indústria (CNI) $(2012,2018)$, com os mais renomeados institutos brasileiros de pesquisa, Datafolha e lbope, respectivamente, com dados de 2011 a 2018, que revelam a importância da avaliação de qualidade e satisfação. No entretanto, apontam insatisfações da população que variam de 54 a 93\% (CONSELHO FederAl DE MedicinA, 2014; 2015; 2018). E, ainda, que elevados percentuais de brasileiros avaliam a saúde pública como ruim ou péssima, que aumentou de $61 \%$, em 2011, para 75\% em 2018 (CONFEDERAÇÃo NACIONAL DA INDÚSTRIA, 2012; 2018), que variam conforme a perspectiva de análise e abordagem dessas pesquisas, em especial quanto ao uso recente dos serviços, seja na saúde pública ou suplementar.

No entanto, em uma pesquisa sistemática nas principais bases de artigos científicos do Brasil (Medline; Lilacs; Scielo), além de ter obtido resultados extremamente escassos, não se identificou nenhuma metodologia robusta de avaliação de qualidade e satisfação através de instrumentos padronizados e validados e/ou de larga utilização no contexto de saúde do Brasil (Figura 1). Esses achados estão alinhados com os resultados de uma revisão sistemática extensiva, entre 1990 e 2013, nas principais bases bibliográficas de publicações brasileiras em saúde pública, na qual Volpato (LUCIANA FERNANDES VolPATO, 2014)(2014) identificou poucas publicações com características voltadas à percepção dos usuários e/ou dos profissionais referentes à qualidade dos serviços públicos de saúde, também não tendo identificado instrumentos ou escalas validadas de mensuração de satisfação e/ou qualidade em saúde no Brasil.

A partir de uma análise integrativa realizada por Giese e Cote (2000 apud Vinagre, 2008), podem-se sintetizar os achados de alguns estudos sobre as bases da avaliação da satisfação, comparando as definições conceptuais, as respostas, o enfoque e o momento da análise da satisfação (Tabela 7, anexo). 
Figura 1 - Bibliometria de estudos de avaliação em saúde no Brasil (1990 - 2018)

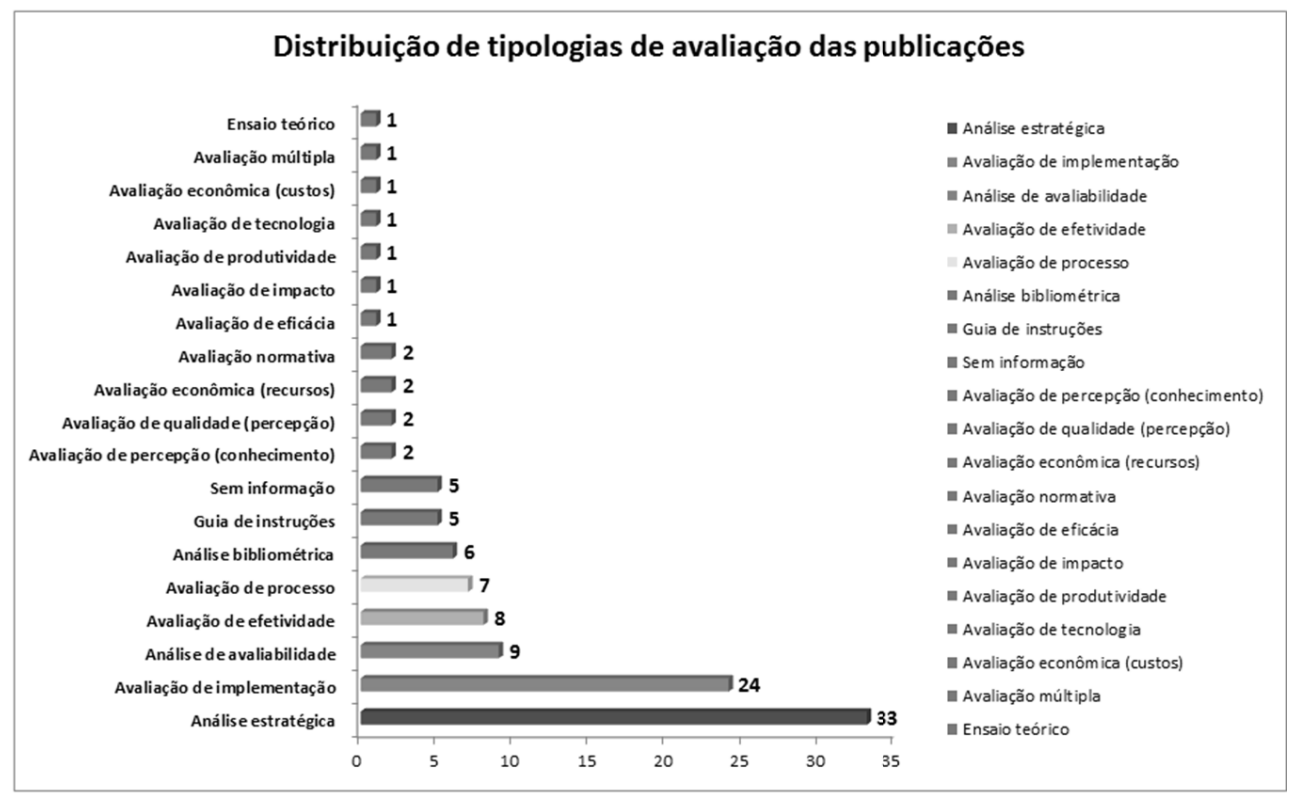

Fonte: elaboração própria.

No escopo da saúde, uma revisão da literatura mundial aponta que a satisfação do usuário é multifacetada e de difícil mensuração (ESPERIDIÃO; TRAD, 2005; ESPERIDIÃO, 2009), sendo de interesse maior para os decisores de saúde (AHARONY; STRASSER, 1993 apud ESPERIDIÃO; TRAD, 2005, p.304). Nesse contexto, Vinagre (2008) enfatiza a complexidade de aferição dos serviços pelos aspectos da intangibilidade (ausência de atributos físicos) dos serviços (PARASURAMAN et al., 1991b) e o fato dos serviços constituírem-se essencialmente enquanto processos, sendo afetados por interações e atividades (GRönRoos, 1990), ou seja, dependente de aspectos relacionais entre usuários e prestadores de serviços.

$\mathrm{Na}$ pesquisa da literatura aplicada sobre mensuração de satisfação e/ou qualidade em saúde no Brasil, destacaram-se poucos trabalhos: três trabalhos de pequeno porte de aplicação da Servqual em contextos específicos (HERcos; Berezovsky, 2004; Borges et al., 2006; Cruz; Melleiro, 2007). Também foram identificados dois trabalhos com sistematização da Servqual, mas com aplicação em amostra resumida no Brasil (AlbuqUerque, 2012; RosALEM, 2013). Esses trabalhos aplicaram apenas a versão original da escala Servqual, sendo de difícil mensuração dos resultados comparativos pela ausência de validação transcultural. 
Em uma meta-análise sobre o assunto, Szymanski e Henard (2001) salientam que as investigações sobre satisfação de consumidores focam predominantemente os efeitos sobre a satisfação através das variáveis preditoras, quais sejam as expectativas, a desconfirmação (como preditor com efeito dominante) e, ainda, citam outros preditores como a equidade (como forte preditor, quando analisada conjuntamente com as expectativas e as emoções) e, a percepção (com um efeito preditor muito mais fraco, quando analisada conjuntamente com as expectativas de desempenho).

Atribui-se a Parasuraman et al. (1985a) a elaboração de um instrumento de mensuração de satisfação denominado de escala Service Quality - Servqual . Nessa escala, foi proposta a medição de qualidade do serviço, baseado no modelo gap model de satisfação de Oliver (1980), que afirma que a satisfação do cliente é uma função da diferença entre expectativa e desempenho. Ou seja, nesse modelo a posição da percepção do cliente sobre a qualidade de serviço percebida depende da natureza e da extensão da discrepância entre a expectativa de serviço e o desempenho percebido.

A perspectiva de avaliação da qualidade na metodologia do gap model é operacionalizada pela comparação algébrica entre a expectativa dos usuáriosutilizadores e a satisfação percebida em organizações de serviços (PARASURAMAN et al., 1985A), que, em seguida, transformou-se na escala Servqual (PARASURAMAN et al., 1988; 1991b), com posterior adaptação para aplicação em serviços de saúde (BABAKUS; MANGOLD, 1992), por meio de análises de confiabilidade e validade (por meio de correlação e análise fatorial exploratória) concluíram que a escala Servqual é confiável e válida no ambiente hospitalar e em outros serviços de saúde.

Inicialmente, a escala Servqual foi desenvolvida com 97 itens, tomando como base as 10 dimensões da qualidade (PARASURAMAN et al., 1985a; 1991a) e, por fim, consolidou-se um instrumento com 22 questões, que foram redistribuídas das dez (10) dimensões originais para as atuais cinco (5) dimensões da escala Servqual (PARASURAMAN et al., 1991a; BerRy et al., 1994).

Uma breve análise da escala proposta na iniciativa do Gespública (BRASIL, 2014) revela muita similaridade com as cinco dimensões e com as 22 questões da escala original Servqual (PARASURAMAN et al., 1991a; BERRY et al., 1994), portanto, aparentemente, na composição da escala de satisfação que compõe o IPPS não houve um processo de adequação através de tradução transcultural e análises de confiabilidade e validade (por meio de correlação e análise fatorial exploratória).

Face à escassez de instrumentos oficiais para medir a satisfação do usuário dos serviços públicos de saúde no Brasil, nesta investigação elaborou-se uma proposta de estratégia de mensuração de avaliação de satisfação dos usuários-utilizadores, 
pautada em princípios científicos, embasada na tradução e validação transcultural multicêntrica da escala Servqual para identificar os constructos (ideias-forças) relevantes/importantes na visão de especialistas, gestores e profissionais, além da validação de campo através de uma amostra de usuários do SUS.

\section{Metodologia}

A natureza da pesquisa caracteriza-se por uma metodologia avaliativa do tipo observacional (controle de possíveis influências intencionais no objeto pesquisado), transversal, com abordagem por método misto (qualitativo e quantitativo) de avaliação durante a etapa de validação metodológica, e instrumental, por agentes chaves da amostra (gestores, profissionais e usuários da saúde).

$\mathrm{Na}$ exploração inicial dos conhecimentos prévios dos agentes de decisão, seguiram-se os princípios de Sampieri et al. (2006), que sugerem a amostragem por conveniência quando a investigação está centrada em indivíduos ou grupos portadores de um ou vários atributos que possam contribuir para o desenvolvimento de uma teoria. Citam a limitação de generalização de resultados, mas também a boa captação e compreensão dos significados em contextos específicos.

Sendo assim, objetivando operacionalizar uma adaptação transcultural da escala Servqual, no âmbito da pesquisa de tese de Galba Freire Moita, na Universidade de Coimbra, conforme aprovada na Plataforma Brasil (CAAE: 54972816.9.0000.5051), selecionou-se inicialmente um grupo piloto de gestores e profissionais para formar um painel de especialistas com 25 profissionais, ouvidores e gestores de qualidade (fase 1) que, em seguida, foi validada por um grupo piloto de 170 profissionais (fase 2). Em seguida, aplicou-se uma pesquisa de campo de validação por 506 usuários de 15 unidades de saúde do SUS. A proposta de estudo inicial foi apresentada publicamente em congresso da Abrasco (MoITA et al., 2017), destacando apenas as etapas da investigação, mas com fluxos de aplicação, análise e resultados originais publicados e detalhados neste trabalho.

A partir dos conceitos e possíveis categorias analíticas que emergiram da análise crítica da escala Servqual, propôs-se um embasamento teórico-metodológico para estruturar instrumentos (questionários semiestruturados) construídos em etapas e fases sucessivas de colaboração com grupos de 195 especialistas, profissionais, gestores provenientes de 10 estados (províncias) brasileiros: Bahia, Ceará, Goiás, Maranhão, Mato Grosso, Pará, Piauí, Rio Grande do Norte, Rondônia e o Distrito Federal, e, posteriormente, envolver usuários do SUS visando mapear as preferências e relevâncias atribuídas pelos respondentes quanto aos constructos (ideias-forças) propostos. 
Inicialmente nos dois painéis de especialistas iniciais foi consenso que as cinco macrodimensões originais do método Servqual deveriam ser mantidas para garantir o mínimo de comparabilidade na escala final. Em seguida, analisaram as 22 questões originais e propuseram a tradução de cada uma delas por um conceito que poderia ser percebido de forma mais adequada pelos usuários do SUS que originaram as 22 subdimensões propostas para valoração, devidamente vinculadas às cinco macrodimensões da escala Servqual.

Após as três etapas de análise de literatura e de preparação de instrumentos de coleta de dados, a aplicação da pesquisa foi dividida em quatro fases sucessivas e incrementais de adaptação, sintetizadas na Figura 2.

Figura 2 - Fluxo do processo de validação de constructos adaptados ao SUS (qualidade percebida)

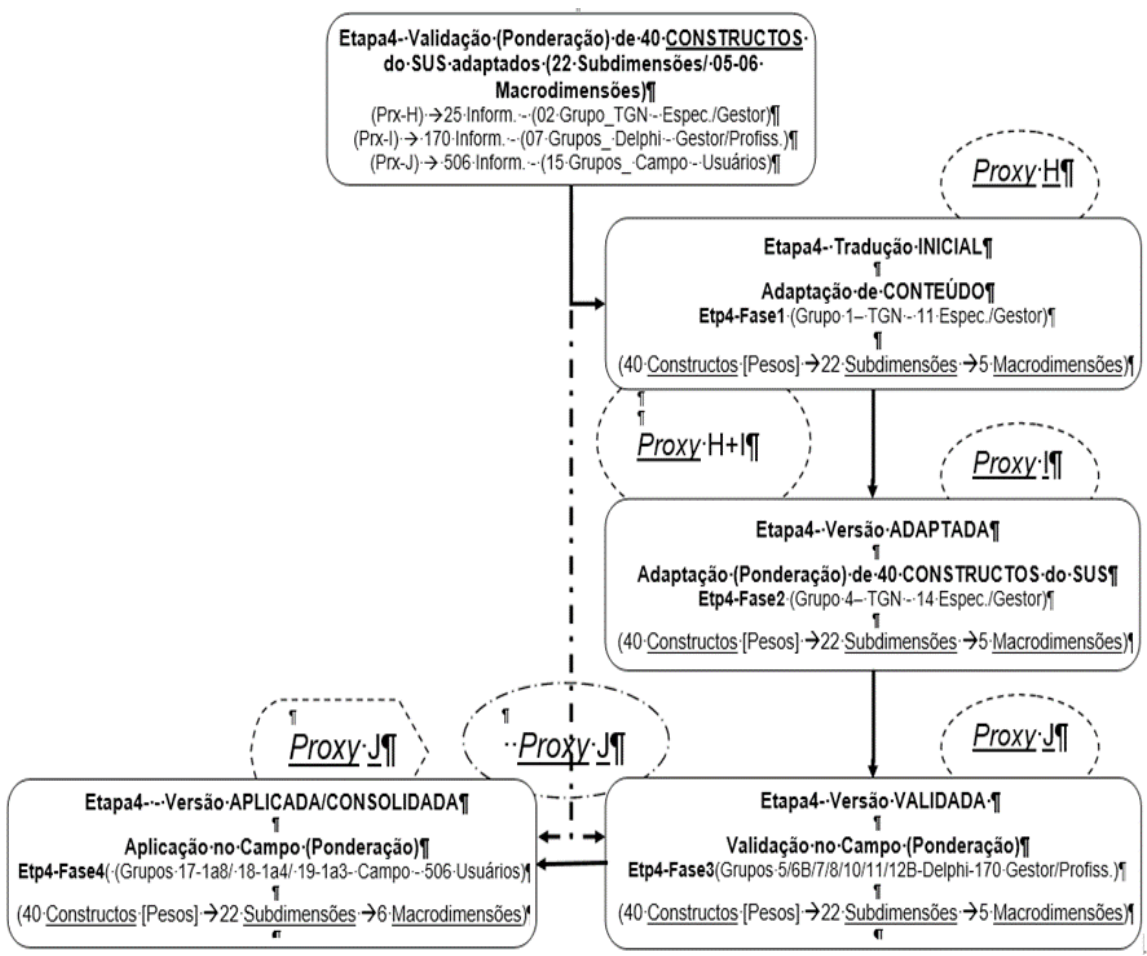

Fonte: elaboração própria.

Esses fluxos têm suas análises complementadas pelo esquema lógico de análise de constructos de qualidade e das macrodimensões e subdimensões de qualidade. Na primeira etapa, no âmbito do estudo da etapa 4, procedeu-se à análise estatística de dados das proxies da valoração das subdimensões de qualidade, além de seus reflexos nas macrodimensões de qualidade, descritos a seguir: 


\section{Quadro 1 - Síntese das etapas do processo analítico}

\begin{tabular}{|l|l|l|l|l|l|}
\hline Análise cód. & \multicolumn{2}{|c|}{ Etapas/Estudo } & Fases & Proxy & Informantes (N) / Categorias \\
\hline A1) Análises de respostas atribuídas através de 4 proxies & (pesos atribuídos para os constructos) \\
\hline A1.a)-Inicial & Etp4- ciclo1 & 1 & H & 25 espec./gestor \\
\hline A1.b)-Ajuste & Etp4- ciclo1 & 2 & I & 170 espec./gestor \\
\hline A1.c)-Síntese & Etp4-ciclo1 & 3 & H + I & 195 espec./gestor \\
\hline A1.d)-Campo & Etp4-ciclo2 & 4 & J & 506 usuários \\
\hline
\end{tabular}

A2) Análises de respostas calculadas através de 4 proxies (pesos refletidos para as subdimensões):

\begin{tabular}{|l|l|l|l|l|}
\hline A2.a)-Inicial & Etp4 - ciclo1 & 1 & H & 25 espec./gestor \\
\hline A2.b)-Ajuste & Etp4 - ciclo1 & 2 & $\mathrm{I}$ & 170 espec./gestor \\
\hline A2.c)-Síntese & Etp4 - ciclo1 & 3 & $\mathrm{H}+\mathrm{I}$ & 195 espec./gestor \\
\hline A2.d)-Campo & Etp4 - ciclo2 & 4 & $\mathrm{~J}$ & 506 usuários \\
\hline
\end{tabular}

A3) Análises de respostas calculadas através de um proxy (pesos refletidos para os macrodomínios e para a performance global percebida)

\begin{tabular}{l|l|l|l|l} 
A3.a)-Campo & Etp4-ciclo2 & 4 & J & 506 usuários
\end{tabular}

Na primeira fase, reuniram-se dois grupos somando 25 especialistas (ouvidores e gestores de qualidade de unidades de saúde) que analisaram o conteúdo das 22 questões originais e sugeriram um conjunto de constructos dentro da realidade dos pacientes do SUS. Ainda nessa primeira fase, o instrumento construído foi objeto de análise e valoração quanto à relevância e à importância de cada um dos constructos propostos, estruturando-se um novo instrumento com os constructos que obtiveram relevância com médias superiores a 3 (relevantes e muito relevantes). Em seguida, formaram-se sete grupos Delphi de profissionais que analisaram e atribuíram valoração a cada um dos 40 constructos propostos pelo painel de especialista inicial.

Estruturou-se a análise em dois proxies ( $\mathrm{H} \mathrm{e} \mathrm{I}$ ) de adequações dos questionários (respostas valoradas simultaneamente para a perspectiva dos usuários_U e para a perspectiva dos profissionais_P). Neste caso, consolidaram-se as 25 respostas dos grupos 1 e 4 (etapa 4, fases 1 e 2) (proxy H). Em seguida, esses resultados passaram pela análise e valoração de sete grupos pilotos de 170 profissionais (proxy I), ambas sempre separadas pelas duas perspectivas: usuários e profissionais.

Na segunda fase montou-se um questionário com os 40 constructos priorizados, seguindo a lógica e as cinco macrodimensões da escala Servqual original. Reuniu-se 
um total de 170 profissionais, em sete grupos Delphi de validação - que consistiu em consultar de forma progressiva as preferências dos participantes a fim de construir bases de consenso por sucessivas consultas ao grupo de decisores de forma escrita e estruturada (MıNAYo et al., 2010), visando ponderar e validar os níveis de preferência (relevâncias/importâncias) dos profissionais quanto à valoração dos constructos de qualidade percebida, propostos na fase inicial.

Em seguida, na terceira fase da pesquisa, um novo instrumento foi validado pela percepção dos profissionais, com 40 constructos, 22 subdimensões e cinco macrodimensões de qualidade/satisfação, que foi aplicado para consolidar os constructos de qualidade percebida quanto aos níveis de preferências (relevâncias/ importâncias) de 506 usuários em atendimento, de 15 unidades de saúde de um grande município da região metropolitana de Fortaleza (proxy J).

Os dados coletados foram tabulados em planilhas e analisados pelas médias ponderadas das notas atribuídas (valoração de importância/relevância) por meio de uma escala ordinal de Likert de cinco níveis ( $1=$ menor nível/grau e 5 = maior nível/grau) de relevância/importância atribuída pelos entrevistados.

Por fim, aplicaram-se aos resultados obtidos as análises descritivas e significância estatística, e pela análise inferencial elaborou-se um modelo de validação com 40 constructos, 22 subdimensões e cinco macrodimensões pela adequação, tradução transcultural e análises de confiabilidade e validade (por meio de correlação e análise fatorial exploratória), que permita futuramente estruturar um instrumento de avaliação de qualidade percebida (satisfação e adequação ao uso), com questões adequadas ao SUS.

\section{Resultados}

Nessa etapa inicial do estudo, propôs-se junto a um grupo de 25 especialistas (ouvidores, gestores de qualidade e profissionais) a análise de cada uma das questões originais da escala Servqual e sua (in) aplicabilidade junto a profissionais e usuários do SUS. Os especialistas chegaram ao consenso de que parte das questões originais da escala original Servqual poderia ter conteúdos de difícil entendimento para os usuários do contexto de saúde do Brasil, sendo necessária uma análise específica de cada questão e posterior tradução conceitual. Isso parece alinhado com os achados de Babakus e Mangold (1992), que validaram apenas 15 questões do conjunto de 22 questões originais da escala Servqual, no contexto de saúde.

A presente investigação foi desenvolvida a partir dos modelos conceituais e conhecimentos gerais de um grupo de 195 especialistas, gestores e profissionais de saúde com o objetivo de medir os níveis de adequação e adaptabilidade de um 
instrumento de mensuração da qualidade percebida, validado internacionalmente e aplicável ao SUS.

Inicialmente, abordou-se uma análise integrada de fases incrementais (fases 1 e 2, proxies $\mathrm{H}$ e I) que se iniciou pela validação de face (fase 1) e aplicou dois instrumentos diferentes (fases 2 e 3), através de uma amostra de 195 informantes especialistas, gestores e profissionais de saúde. Efetivou-se uma análise integrada das respostas obtidas nesses dois instrumentos (proxy $\mathrm{H}+1$ ), pois apresentaram muitas similaridades (40 constructos, 22 subdimensões de constructos e cinco macrodimensões de qualidade percebida). Em fase posterior (fase 3), abordouse a análise da proxy J - 506 informantes (40 constructos, 22 subdimensões de constructos e cinco macrodimensões de qualidade percebida).

Vale lembrar que cada um dos itens poderia ter diferentes quantidades de respostas, pois os informantes poderiam optar por não responder a totalidade dos itens, mas a comparabilidade foi garantida pela análise das médias ponderadas de todas as respostas obtidas.

\section{Validação por profissionais/especialistas (análise descritiva)}

A Tabela 1 apresenta uma análise descritiva das variáveis de caracterização da amostra da proxy $\mathrm{H}+\mathrm{I}$ (195 informantes). Dessa forma, destaca-se que a amostra se mostrou balanceada (Tabela 1) no nível de atenção à saúde que os indivíduos trabalhavam: níveis secundário (34,87\%), primário (14,36\%) e terciário $(28,72 \%)$ de atenção à saúde, além de $22,05 \%$ da categoria outros (estruturas não assistenciais, por exemplo, apenas de gestão ou governança). Grande parte dos indivíduos $(43,62 \%)$ exercia o nível de cargo/função outros (por exemplo, assessores de gestão, profissionais em geral,etc.), e boa parte (27,13\%) exercia o nível de cargo/ função organizacional. Considerou-se a amostra $(n=195)$ bastante qualificada, visto que a maior parte dos indivíduos (50,52\%) possuía pós-graduação e ainda 93,30\% possuíam nível superior; a grande parte dos indivíduos $(48,19 \%)$ possuía mais de 60 meses de experiência e que uma boa parte dos indivíduos $(17,03 \%)$ trabalhava há mais de 60 meses em cargo/função de decisão, enquanto apenas 4,40\% não possuíam experiência em cargo/função de decisão. 
Tabela 1 - Análise descritiva das variáveis de caracterização da amostra (proxy $\mathrm{H}+\mathrm{l}$ )

\begin{tabular}{|c|c|c|c|}
\hline Variáveis & & $\mathrm{N}$ & $\%$ \\
\hline \multirow{4}{*}{$\begin{array}{l}\text { Nível de atenção à } \\
\text { saúde }\end{array}$} & Atenção primária & 28 & $14,36 \%$ \\
\hline & Atenção secundária & 68 & $34,87 \%$ \\
\hline & Atenção terciária & 56 & $28,72 \%$ \\
\hline & Outros & 43 & $22,05 \%$ \\
\hline \multirow{4}{*}{$\begin{array}{l}\text { Nível complexidade de } \\
\text { assistência }\end{array}$} & Baixa & 34 & $17,44 \%$ \\
\hline & Média & 86 & $44,10 \%$ \\
\hline & Alta & 33 & $16,92 \%$ \\
\hline & Outros & 42 & $21,54 \%$ \\
\hline \multirow{4}{*}{ Nível cargo/função } & Sistêmico & 19 & $10,11 \%$ \\
\hline & Organizacional & 51 & $27,13 \%$ \\
\hline & Gerencia de equipe & 36 & $19,15 \%$ \\
\hline & Outros & 82 & $43,62 \%$ \\
\hline \multirow{7}{*}{ Escolaridade } & Analfabeto & 0 & $0,00 \%$ \\
\hline & Ensino básico & 0 & $0,00 \%$ \\
\hline & Ensino fundamental & 0 & $0,00 \%$ \\
\hline & Ensino médio & 13 & $6,70 \%$ \\
\hline & Ensino superior & 56 & $28,87 \%$ \\
\hline & Pós-graduação & 98 & $50,52 \%$ \\
\hline & Mestrado/PhD & 27 & $13,92 \%$ \\
\hline \multirow{8}{*}{ Tempo de experiência } & Não tem & 1 & $0,52 \%$ \\
\hline & Menos de 6 meses & 23 & $11,92 \%$ \\
\hline & 6 - 12 meses & 35 & $18,13 \%$ \\
\hline & $13-24$ meses & 14 & $7,25 \%$ \\
\hline & 25 - 36 meses & 9 & $4,66 \%$ \\
\hline & $37-48$ meses & 8 & $4,15 \%$ \\
\hline & 49 - 60meses & 10 & $5,18 \%$ \\
\hline & $>60$ meses & 93 & $48,19 \%$ \\
\hline
\end{tabular}




\begin{tabular}{llll}
\hline & Não tem & 8 & $4,40 \%$ \\
\hline Menos de 6 meses & 72 & $39,56 \%$ \\
\hline $6-12$ meses & 25 & $13,74 \%$ \\
\hline \multirow{2}{*}{$\begin{array}{l}\text { Tempo em cargo de } \\
\text { decisão }\end{array}$} & $13-24$ meses & 10 & $5,49 \%$ \\
\cline { 2 - 3 } & $25-36$ meses & 17 & $9,34 \%$ \\
\hline $37-48$ meses & 6 & $3,30 \%$ \\
\hline $49-60$ meses & 13 & $7,14 \%$ \\
\hline$>60$ meses & 31 & $17,03 \%$ \\
\hline Enfermeiro & 36 & $18,46 \%$ \\
\hline Engenheiro & 12 & $6,15 \%$ \\
\hline Administrador & 12 & $6,15 \%$ \\
\hline Médico & 10 & $5,13 \%$ \\
\hline Assistente Social & 10 & $5,13 \%$ \\
\hline Outras & 115 & $58,97 \%$ \\
\hline
\end{tabular}

Fonte: elaboração própria.

A análise global do Gráfico 1 permite afirmar que a ampla maioria dos 40 constructos originais obtiveram valoração média elevada (superior ou cerca de 4). O Gráfico 1 mostra que na ampla maioria dos 40 constructos de qualidade (CO1 a CO40) houve variabilidade na valoração atribuída pelos especialistas e profissionais de saúde, de forma indireta, para a perspectiva de usuários e a dos profissionais, sendo que na maioria dos constructos analisados os intervalos de confiança não se sobrepuseram. Dessa forma, em média, os indivíduos tenderam a dar valorações (importância/relevância) com diferenças significativas na ampla maioria dos 40 constructos para a perspectiva de usuários e a dos profissionais, na proxy $\mathrm{H}+\mathrm{l}$. 
Gráfico 1 - Gráfico de barras com intervalos de confiança para os constructos originais - proxy $\mathrm{H}+\mathrm{l}$ (ciclo 1 , estudo 4) (Perspectiva indireta para usuários e profissionais).

Constructos originais - Usuário Proxy $\mathrm{H}+\mathrm{I}$

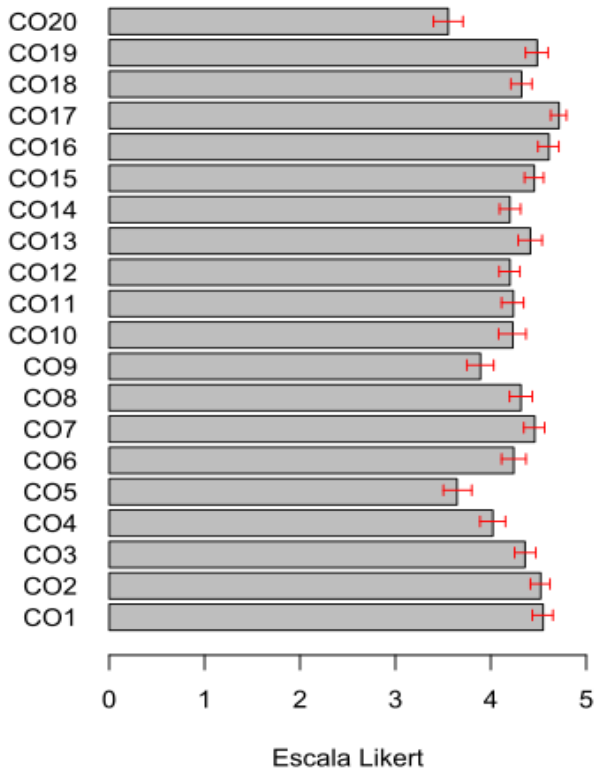

Constructos originais - Profissional Proxy $\mathrm{H}+\mathrm{I}$

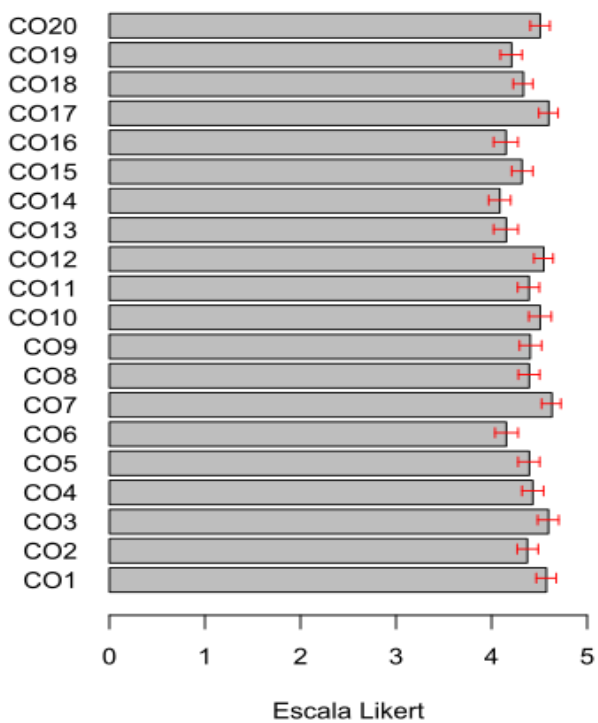

Fonte: elaboração própria.

\section{Constructos originais - Usuário Proxy $\mathrm{H}+\mathrm{I}$}

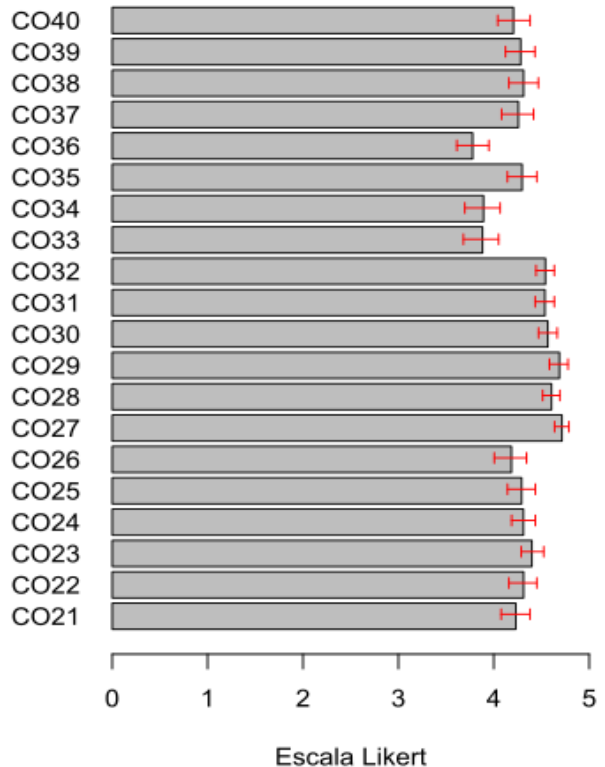

Constructos originais - Profissional Proxy $\mathrm{H}+\mathrm{I}$

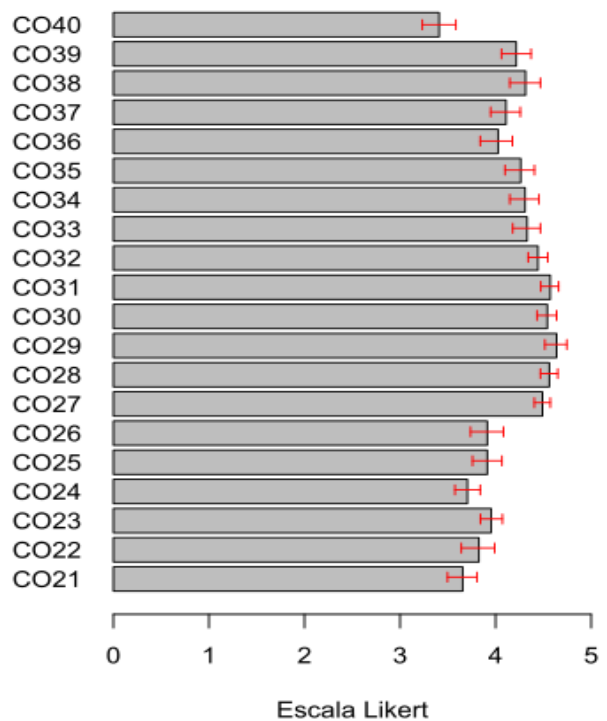


Por sua vez, a análise das subdimensões de constructos de qualidade estruturouse a partir da valoração média atribuída aos constructos pelos indivíduos e calculadas para as subdimensões propostas pelos informantes.

A análise global do Gráfico 2 permite afirmar que a ampla maioria das 22 subdimensões de constructos obtiveram valoração média elevada (superior ou cerca de 4, muito importante/relevante), para as perspectivas de usuários e a dos profissionais, na análise do proxy $\mathrm{H}+\mathrm{l}$, sendo as 22 subdimensões consideradas relevantes/importantes para as próximas fases de investigação.

\section{Gráfico 2 - Gráfico de barras com intervalos de confiança para as subdimensões dos constructos propostos (proxy $\mathrm{H}+\mathrm{l}$ )}

\section{Subdimensões de constructo Usuário}

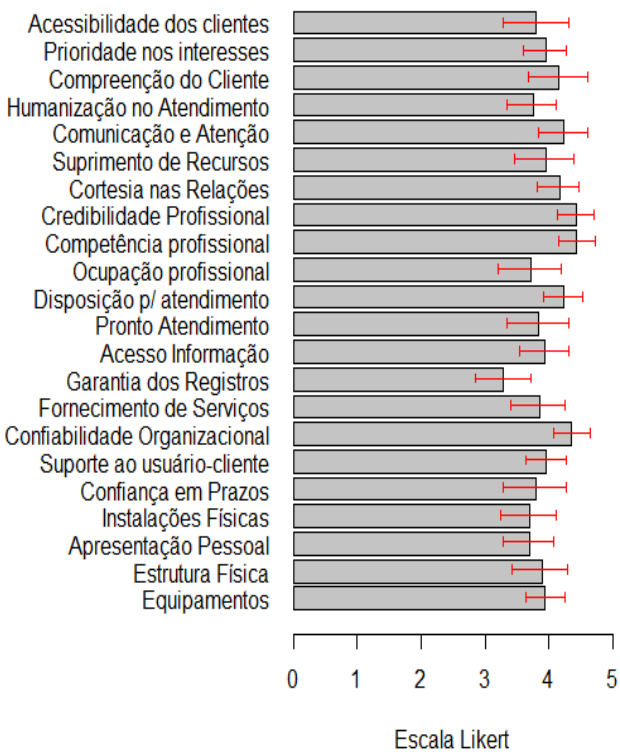

\section{Subdimensões de constructo Profissional}

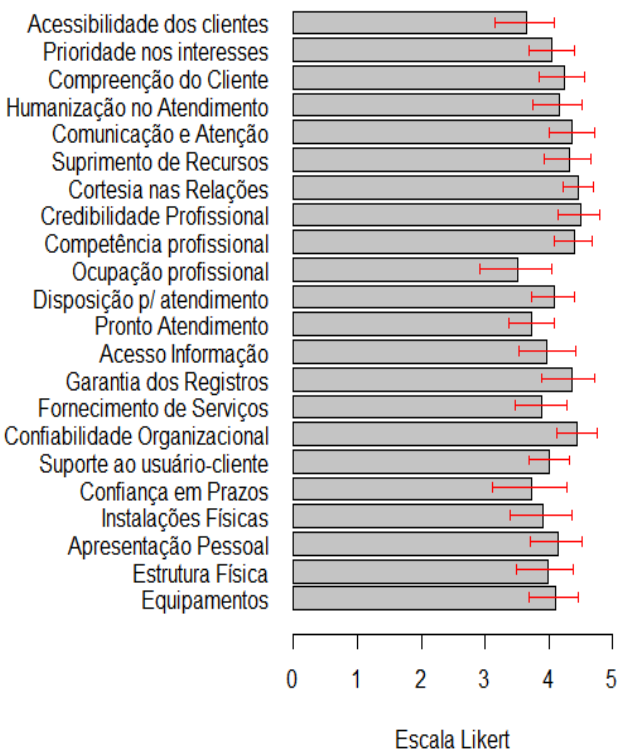

Fonte: elaboração própria.

Da mesma forma, a análise das macrodimensões de qualidade estruturou-se a partir da valoração média atribuída aos constructos pelos indivíduos e calculadas para as macrodimensões propostas pelos informantes.

A análise global do Gráfico 3 permite afirmar que a ampla maioria das cinco macrodimensões de qualidade obtiveram valoração média elevada (superior ou cerca de 4, muito importante/relevante), na análise do proxy $\mathrm{H}+\mathrm{l}$, sendo todas as cinco macrodimensões consideradas relevantes/importantes para análise nas próximas fases de investigação. 
Gráfico 3- Gráfico de barras com intervalos de confiança para as macrodimensões dos constructos propostos (proxy $\mathrm{H}+\mathrm{I}$ )

\section{Macrodimensões - Usuário}

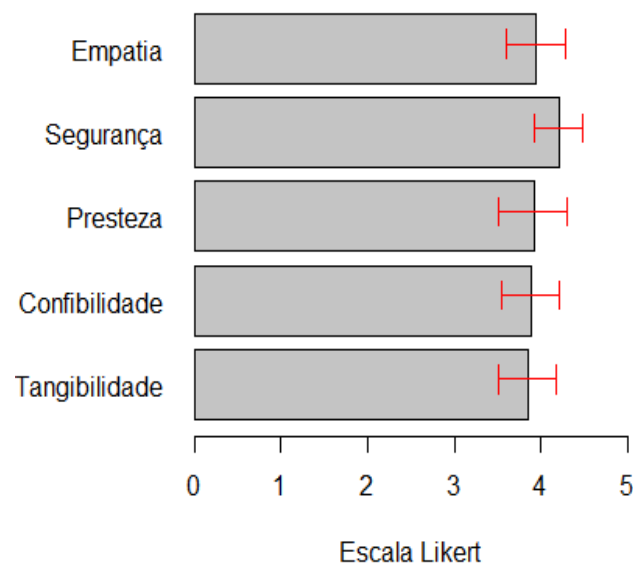

Macrodimensões - Profissional

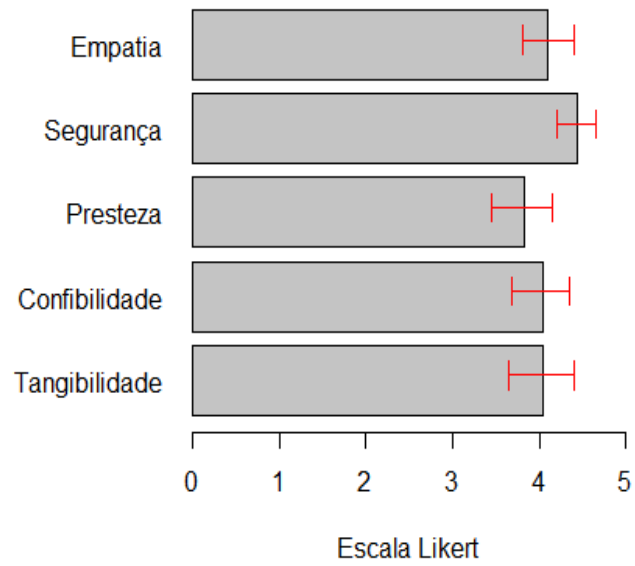

Fonte: elaboração própria.

Dessa análise descritiva pode-se sintetizar que os especialistas e profissionais atribuíram valoração média elevada (superior a 4, muito importante/relevante) para as subcategorias (40 constructos), as categorias (22 subdimensões de qualidade) e as macro categorias (cinco macrodimensões de qualidade) dos itens de análise. Esses resultados consolidaram todos os ítens desse instrumento para a medição de qualidade/satisfação de usuários de saúde, aplicado na fase posterior da investigação (proxy J, fase 3).

Ressalte-se, ainda, que a validação das cinco macrodimensões de qualidade (macrocategorias de análise), na perspectivas de especialistas e profissionais, na proxy $\mathrm{H}+\mathrm{l}$, estão alinhadas com a validação dessas mesmas macrodimensões da escala Servqual, nos estudos de Babakus e Mangold (1992) no contexto de saúde, mas a validação da ampla maioria das 22 subdimensões de constructos propostas (categorias de análise) trata-se de um achado inovador desta investigação que será objeto de aprofundamento da validação nas etapas posteriores.

Aplicou-se uma análise para mensurar os níveis de significância estatística quanto à possível influência de três variáveis mediadoras testadas: nível de atenção à saúde, nível de complexidade da assistência e nível de cargo/função na valoração das 22 subdimensões e das cinco macrodimensões de constructos, para a perspectiva dos usuários e dos profissionais.

Quanto aos resultados do estudo das possíveis influências de três variáveis moderadoras, pode-se sintetizar que houve tendência de influência da variável 
mediadora nível de atenção à saúde na maioria $(\geq 12)$ das 22 subdimensões de constructos, para as perspectivas de usuários (12 subdimensões) e dos profissionais (13 subdimensões), que não houve tendência de influência da variável mediadora nível de complexidade da assistência na ampla maioria $(\geq 14)$ das 22 subdimensões de constructos, para as perspectivas de usuários (17 subdimensões) e dos profissionais (14 subdimensões), e que não houve tendência de influência da variável mediadora nível de cargo/função na ampla maioria ( $\geq 17)$ das 22 subdimensões de constructos nas perspectivas de usuários (17 subdimensões) e dos profissionais (20 subdimensões), na proxy $\mathrm{H}+\mathrm{l}$, que se propõe aprofundar investigações. Por sua vez, também pode-se sintetizar que houve uma tendência de influência da variável mediadora nível de atenção à saúde, em todas as cinco macrodimensões de constructos (tangibilidade, confiabilidade, presteza, segurança e empatia) para as perspectivas de usuários e dos profissionais. Por sua vez, não houve tendência de influência da variável mediadora nível de complexidade da assistência, na ampla maioria das cinco macrodimensões de constructos para a perspectiva de usuários e a dos profissionais, sendo exceções duas macrodimensões (confiabilidade e segurança), na perspectiva de usuários. Também não houve tendência de influência da variável mediadora nível de cargo/função, na ampla maioria das cinco macrodimensões de constructos para a perspectiva de usuários e a dos profissionais, sendo exceções duas macrodimensões (confiabilidade e presteza), na perspectiva de usuários, na proxy $\mathrm{H}+\mathrm{l}$, que se propõe aprofundar investigações.

Diante desses resultados, a comprovação da tendência das variáveis nível de atenção à saúde funcionar enquanto fatores mediadores da ampla maioria das 22 subdimensões de constructos propostas, além de todas as cinco macrodimensões de qualidade originais da escala Servqual, trata-se de um achado inovador desta investigação. Os indícios dos dois fatores mediadores nível de complexidade da assistência e nível de escolaridade cargo/função funcionarem enquanto fatores mediadores das 22 subdimensões e cinco macrodimensões de constructos propostas foram aprofundados nas etapas posteriores (proxy J, fase 3).

\section{Validação por usuários (análise descritiva)}

Em seguida, no ciclo 2, fase 3, voltou-se à validação na perspectiva direta de 506 informantes usuários do SUS. Vale lembrar que cada um dos itens poderia ter diferentes quantidades de respostas, pois os informantes poderiam optar por não responder à totalidade dos itens, mas a comparabilidade foi garantida pela análise das médias ponderadas de todas as respostas. Aplicaram-se as análises descritivas e de significância estatísticas das respostas obtidas. 
Na Tabela 2 destaca-se que a amostra se mostrou diversificada (Tabela 26) no nível de atenção à saúde que os indivíduos estavam em atendimento: níveis primário $(47,63 \%)$, secundário $(27,67 \%)$ e terciário $(24,70 \%)$ de atenção à saúde. A maior parte dos indivíduos na amostra (52,37\%) estava em atendimento em unidades de média complexidade, enquanto $47,63 \%$ estava em atendimento em unidades de baixa complexidade. Não houve entrevista em unidades de alta complexidade da assistência, por exemplo, em hospitais de grande porte. Considerou-se a amostra ( $n=506$ ) razoavelmente representativa da realidade dos usuários do SUS, visto que a maior parte dos indivíduos $(48,62 \%)$ possuía até o ensino basilar (analfabeto e ensino básico), seguidos por boa parte $(39,01 \%)$ que possuía ensino médio e por $13,44 \%$ de indivíduos que possuíam ensino fundamental, e, ainda, a maioria dos indivíduos $(73,27 \%)$ era do sexo feminino -- desequilibrada por histórica demanda reduzidas de homens -, a faixa de idade mais frequente entre os indivíduos foi a de 30 a 39 anos (23,91\%), seguida por 20 a 29 anos (21,94\%) e 40 a 49 anos $(15,02 \%)$.

\section{Tabela 2 - Análise descritiva das variáveis de caracterização selecionadas - proxy J (Visão de usuários).}

\begin{tabular}{|c|c|c|c|}
\hline Variáveis & & $\mathrm{N}$ & $\%$ \\
\hline \multirow{4}{*}{ Nível de atenção à saúde } & Atenção primária & 241 & $47,63 \%$ \\
\hline & Atenção secundária & 140 & $27,67 \%$ \\
\hline & Atenção terciária & 125 & $24,70 \%$ \\
\hline & Outros & 0 & $0,00 \%$ \\
\hline \multirow{4}{*}{$\begin{array}{l}\text { Nível Complexidade da } \\
\text { assistência }\end{array}$} & Baixa & 241 & $47,63 \%$ \\
\hline & Média & 265 & $52,37 \%$ \\
\hline & Alta & 0 & $0,00 \%$ \\
\hline & Outros & 0 & $0,00 \%$ \\
\hline \multirow{7}{*}{ Escolaridade } & Analfabeto & 22 & $4,35 \%$ \\
\hline & Ensino básico & 224 & $44,27 \%$ \\
\hline & Ensino fundamental & 68 & $13,44 \%$ \\
\hline & Ensino médio & 183 & $36,17 \%$ \\
\hline & Ensino superior & 8 & $1,58 \%$ \\
\hline & Pós-graduação & 1 & $0,20 \%$ \\
\hline & Mestrado/ PhD & 0 & $0,00 \%$ \\
\hline
\end{tabular}




\begin{tabular}{llll}
\hline Sexo & Masculino & 134 & $26,53 \%$ \\
\hline Feminino & 370 & $73,27 \%$ \\
\hline Outros & 1 & $0,20 \%$ \\
\hline Até 19 anos & 4 & $0,79 \%$ \\
\hline 20 a 29 anos & 111 & $21,94 \%$ \\
\hline 30 a 39 anos & 121 & $23,91 \%$ \\
\hline 40 a 49 anos & 76 & $15,02 \%$ \\
\hline 50 a 59 anos & 72 & $14,23 \%$ \\
\hline 60 a 69 anos & 61 & $12,06 \%$ \\
\hline 60 a 79 anos & 36 & $7,11 \%$ \\
\hline 80 anos ou mais & 25 & $4,94 \%$
\end{tabular}

Fonte: elaboração própria.

A análise global do Gráfico 4 permite afirmar que todos os 40 constructos originais propostos obtiveram valoração média superior ao nível 3 (importante/ relevante), sendo, portanto, considerados relevantes/importantes para estruturar as questões do instrumento de pesquisa dos usuários do SUS.

Gráfico 4 - Gráfico de barras com intervalos de confiança para os constructos de qualidade - proxy J (Visão de usuários).
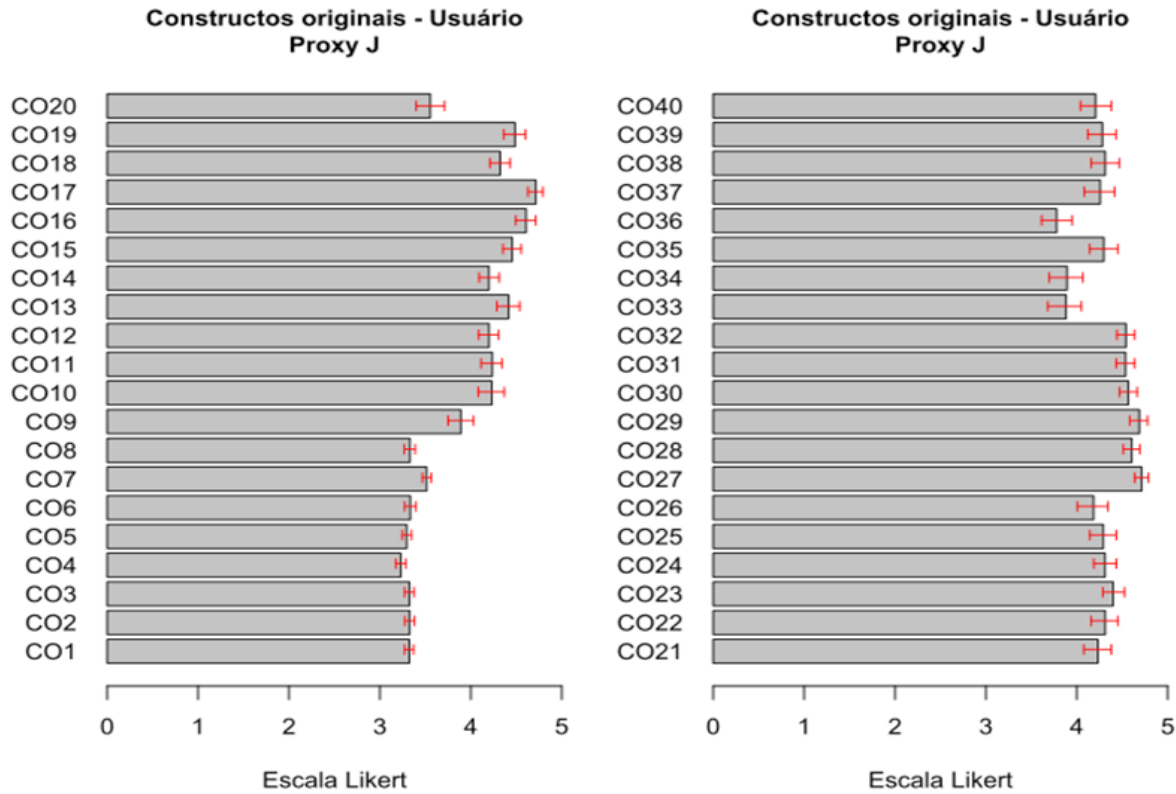

Fonte: elaboração própria. 
Por sua vez, a análise das subdimensões de constructos de qualidade estruturouse a partir da valoração média atribuída aos constructos pelos indivíduos e calculadas para as subdimensões propostas pelos informantes.

A análise global do Gráfico 5 permite afirmar que a ampla maioria (18) das 22 subdimensões de constructos obtiveram valoração média elevada (superior a 3, importante/relevante), na análise da proxyJ, sendo as 22 subdimensões consideradas relevantes/importantes para as próximas fases de investigação, na estruturação do instrumento de pesquisa de usuários. Na ampla maioria das 22 subdimensões de constructos avaliadas para a visão de usuários, houve diferença significativa da valoração média obtida somente em três subdimensões (suprimentos de recursos, ocupação profissional e confiança em prazos), que formaram um grupo com valorações significativamente menores em relação às demais, como também na subdimensão confiabilidade organizacional com valoração significativamente maior em relação às demais, uma vez que todas as demais 18 subdimensões tiveram intervalos de confiança que se sobrepuseram.

Por sua vez, a análise das macrodimensões de qualidade estruturou-se a partir da valoração média atribuída aos constructos pelos indivíduos e calculadas para as macrodimensões propostas pelos informantes. A Tabela 3 apresenta uma análise descritiva das valorações médias obtidas pelas macrodimensões de qualidade, na análise da proxy J, na visão de usuários de saúde.

A análise global da Tabela 3 permite afirmar que todas as cinco macrodimensões de qualidade obtiveram valoração média elevada (superior a 3, importante/ relevante), na análise do proxy J, sendo todas as cinco macrodimensões consideradas relevantes/importantes para estruturar as questões do instrumento de pesquisa dos usuários do SUS.

Tabela 3 - Análise descritiva das macrodimensões de constructos - proxy J (Visão de usuários).

\begin{tabular}{lccl}
\hline Macrodimensões & Média & D.P. & I.C-95\% ${ }^{1}$ \\
\hline Tangibilidade & 3,35 & 0,50 & {$[3,31 ; 3,39]$} \\
\hline Confiabilidade & 3,16 & 0,28 & {$[3,14 ; 3,19]$} \\
\hline Presteza & 3,07 & 0,24 & {$[3,05 ; 3,09]$} \\
\hline Segurança & 3,19 & 0,31 & {$[3,16 ; 3,21]$} \\
\hline Empatia & 3,10 & 0,24 & {$[3,08 ; 3,12]$} \\
\hline & ${ }^{1}$ Intervalo Bootstrap: &
\end{tabular}

Fonte: elaboração própria. 
Dessa análise descritiva pode-se sintetizar que os usuários atribuíram valoração média elevada (superior a 3, importante/relevante) para as subcategorias (40 constructos), as categorias (22 subdimensões de qualidade) e as macro categorias (cinco macrodimensões de qualidade) dos itens de análise. Esses resultados podem subsidiar a construção de um novo instrumento, pela estruturação de questões validadas a partir destes ítens de avaliação validados, em uma escala inovadora de medição de qualidade/satisfação de usuários de saúde.

Ressalte-se, ainda, que a validação das cinco macrodimensões de qualidade (macrocategorias de análise), na perspectivas de usuários do SUS, na proxy J, estão alinhadas com a validação dessas mesmas macrodimensões da escala Servqual, nos estudos de Babakus e Mangold (1992) no contexto de saúde, mas a validação da ampla maioria das 22 subdimensões de constructos propostas (categorias de análise) trata-se de um achado inovador desta investigação.

Aplicou-se uma análise para mensurar os níveis de significância estatística quanto à possível influência de três variáveis mediadoras testadas: nível de atenção à saúde, nível de complexidade da assistência e nível de cargo/função na valoração das 22 subdimensões e das cinco macrodimensões de constructos, para a perspectiva dos usuários.

Tabela 4 - Comparação das subdimensões dos constructos em relação aos níveis de atenção à saúde (proxy J) (Visão de usuários).

\begin{tabular}{|c|c|c|c|c|c|c|c|}
\hline $\begin{array}{l}\text { Subdimensões de constructos/ } \\
\text { nível de atenção à saúde }\end{array}$ & Média & E.P. & Média & E.P. & Média & E.P. & Valor-p ${ }^{1}$ \\
\hline Equipamentos & 3,05 & 0,04 & 3,59 & 0,04 & 3,45 & 0,05 & 0,000 \\
\hline Estrutura física & 3,24 & 0,04 & 3,56 & 0,04 & 3,49 & 0,04 & 0,000 \\
\hline Apresentação pessoal & 3,20 & 0,04 & 3,49 & 0,05 & 3,66 & 0,04 & 0,000 \\
\hline Instalações físicas & 3,20 & 0,04 & 3,62 & 0,04 & 3,41 & 0,05 & 0,000 \\
\hline Confiança em prazos & 2,95 & 0,03 & 2,96 & 0,04 & 2,74 & 0,06 & 0,001 \\
\hline Fornecimento de serviços & 3,02 & 0,03 & 3,40 & 0,03 & 3,07 & 0,03 & 0,000 \\
\hline Garantia dos registros & 3,14 & 0,02 & 3,16 & 0,04 & 3,00 & 0,03 & 0,001 \\
\hline Acesso informação & 3,16 & 0,02 & 3,13 & 0,03 & 3,15 & 0,03 & 0,614 \\
\hline Pronto atendimento & 2,93 & 0,02 & 3,24 & 0,04 & 2,99 & 0,03 & 0,000 \\
\hline Disposição p/ atendimento & 3,13 & 0,02 & 3,19 & 0,03 & 3,06 & 0,02 & 0,009 \\
\hline
\end{tabular}




\begin{tabular}{|l|l|l|l|l|l|l|l}
\hline Ocupação profissional & 2,88 & 0,03 & 3,01 & 0,01 & 3,01 & 0,01 & 0,000 \\
\hline Competência profissional & 3,25 & 0,03 & 3,36 & 0,04 & 3,26 & 0,04 & 0,070 \\
\hline Credibilidade profissional & 3,27 & 0,03 & 3,47 & 0,04 & 3,35 & 0,04 & 0,001 \\
\hline Cortesia nas relações & 3,18 & 0,03 & 3,37 & 0,04 & 3,20 & 0,04 & 0,000 \\
\hline Suprimento de recursos & 2,81 & 0,03 & 2,99 & 0,01 & 2,99 & 0,01 & 0,000 \\
\hline Comunicação e atenção & 3,14 & 0,02 & 3,10 & 0,03 & 3,06 & 0,02 & 0,102 \\
\hline Humanização no atendimento & 3,16 & 0,02 & 3,20 & 0,03 & 3,08 & 0,02 & 0,020 \\
\hline Compreensão do cliente & 3,07 & 0,02 & 3,24 & 0,04 & 3,11 & 0,03 & 0,000 \\
\hline Prioridade nos interesses & 3,11 & 0,02 & 3,01 & 0,01 & 3,06 & 0,02 & 0,001 \\
\hline Acessibilidade dos clientes & 2,91 & 0,03 & 3,07 & 0,02 & 3,06 & 0,02 & 0,000 \\
\hline
\end{tabular}

${ }^{1}$ Teste de Kruskal-Wallis.

Fonte: elaboração própria.

Tabela 5 - Comparação das subdimensões de constructos em relação aos níveis de complexidade da assistência - proxy J (Visão de usuários).

\begin{tabular}{|l|l|l|l|l|l|}
\hline $\begin{array}{l}\text { Subdimensõesdeconstructosdo } \\
\text { usuário / nível de complexidade }\end{array}$ & Baixa & \multicolumn{3}{|c|}{ Média } & \\
\hline Equipamentos & 3,05 & 0,04 & 3,53 & 0,03 & 0,000 \\
\hline Estrutura física & 3,24 & 0,04 & 3,53 & 0,03 & 0,000 \\
\hline Apresentação pessoal & 3,20 & 0,04 & 3,57 & 0,03 & 0,000 \\
\hline Instalações físicas & 3,20 & 0,04 & 3,52 & 0,03 & 0,000 \\
\hline Confiança em prazos & 2,95 & 0,03 & 2,86 & 0,04 & 0,073 \\
\hline Suporte ao usuário-cliente & 3,16 & 0,02 & 3,17 & 0,02 & 0,588 \\
\hline Confiabilidade organizacional & 3,35 & 0,04 & 3,66 & 0,03 & 0,000 \\
\hline Fornecimento de serviços & 3,02 & 0,03 & 3,24 & 0,03 & 0,000 \\
\hline Garantia dos registros & 3,14 & 0,02 & 3,09 & 0,02 & 0,164 \\
\hline Acesso informação & 3,16 & 0,02 & 3,14 & 0,02 & 0,342 \\
\hline Pronto atendimento & 2,93 & 0,02 & 3,12 & 0,03 & 0,000 \\
\hline Disposição p/ atendimento & 3,13 & 0,02 & 3,13 & 0,02 & 0,903 \\
\hline Ocupação profissional & 2,88 & 0,03 & 3,01 & 0,01 & 0,000 \\
\hline Competência profissional & 3,25 & 0,03 & 3,31 & 0,03 & 0,199 \\
\hline Credibilidade profissional & 3,27 & 0,03 & 3,41 & 0,03 & 0,002 \\
\hline
\end{tabular}




\begin{tabular}{l|l|l|l|l|l}
\hline Cortesia nas relações & 3,18 & 0,03 & 3,29 & 0,03 & 0,005 \\
\hline Suprimento de recursos & 2,81 & 0,03 & 2,99 & 0,01 & 0,000 \\
\hline Comunicação e atenção & 3,14 & 0,02 & 3,08 & 0,02 & 0,054 \\
\hline Humanização no atendimento & 3,16 & 0,02 & 3,15 & 0,02 & 0,823 \\
\hline Compreensão do cliente & 3,07 & 0,02 & 3,18 & 0,02 & 0,001 \\
\hline Prioridade nos interesses & 3,11 & 0,02 & 3,03 & 0,01 & 0,001 \\
\hline Acessibilidade dos clientes & 2,91 & 0,03 & 3,06 & 0,02 & 0,000 \\
\hline
\end{tabular}

${ }^{1}$ Teste de Mann-Whitney

Fonte: elaboração própria.

\section{Tabela 6 - Comparação das subdimensões de questões validadas em relação aos níveis de escolaridade de usuários - proxy J (Visão de usuários).}

\begin{tabular}{|c|c|c|c|c|c|c|c|c|c|}
\hline \multirow{2}{*}{$\begin{array}{l}\text { Subdimensões de constructos } \\
\text { do usuário / escolaridade }\end{array}$} & \multicolumn{2}{|l|}{ Basilar } & \multicolumn{2}{|c|}{ Fundamental } & \multicolumn{2}{|l|}{ Médio } & \multicolumn{2}{|c|}{ Superior } & \multirow{2}{*}{ Valor-p ${ }^{1}$} \\
\hline & Média & E.P. & Média & E.P. & Média & E.P. & Média & E.P. & \\
\hline Equipamentos & 3,36 & 0,03 & 3,17 & 0,08 & 3,29 & 0,04 & 3,31 & 0,23 & 0,351 \\
\hline Estrutura física & 3,49 & 0,03 & 3,23 & 0,08 & 3,36 & 0,04 & 3,11 & 0,15 & 0,003 \\
\hline Apresentação pessoal & 3,44 & 0,04 & 3,19 & 0,07 & 3,44 & 0,05 & 3,33 & 0,17 & 0,008 \\
\hline Instalações físicas & 3,45 & 0,04 & 3,23 & 0,08 & 3,34 & 0,04 & 3,11 & 0,20 & 0,053 \\
\hline Confiança em prazos & 2,89 & 0,04 & 2,99 & 0,06 & 2,88 & 0,04 & 3,00 & 0,00 & 0,494 \\
\hline Suporte ao usuário-cliente & 3,26 & 0,03 & 3,13 & 0,04 & 3,08 & 0,02 & 3,00 & 0,00 & 0,000 \\
\hline Confiabilidade organizacional & 3,63 & 0,03 & 3,32 & 0,07 & 3,46 & 0,04 & 3,56 & 0,18 & 0,000 \\
\hline Fornecimento de serviços & 3,19 & 0,03 & 3,04 & 0,05 & 3,10 & 0,03 & 3,28 & 0,12 & 0,048 \\
\hline Garantia dos registros & 3,18 & 0,03 & 3,06 & 0,03 & 3,06 & 0,03 & 2,89 & 0,11 & 0,002 \\
\hline Acesso informação & 3,22 & 0,03 & 3,08 & 0,03 & 3,10 & 0,02 & 3,00 & 0,00 & 0,001 \\
\hline Pronto atendimento & 3,08 & 0,03 & 2,94 & 0,03 & 3,00 & 0,02 & 3,22 & 0,15 & 0,042 \\
\hline Disposição p/ atendimento & 3,19 & 0,03 & 3,08 & 0,03 & 3,07 & 0,02 & 3,22 & 0,15 & 0,002 \\
\hline Ocupação profissional & 2,95 & 0,02 & 2,92 & 0,04 & 2,95 & 0,02 & 3,00 & 0,00 & 0,763 \\
\hline Competência profissional & 3,36 & 0,03 & 3,19 & 0,06 & 3,22 & 0,03 & 3,44 & 0,18 & 0,005 \\
\hline Credibilidade profissional & 3,44 & 0,03 & 3,24 & 0,06 & 3,27 & 0,04 & 3,44 & 0,18 & 0,003 \\
\hline Cortesia nas relações & 3,35 & 0,03 & 3,16 & 0,04 & 3,14 & 0,03 & 3,33 & 0,17 & 0,000 \\
\hline Suprimento de recursos & 2,92 & 0,02 & 2,88 & 0,04 & 2,90 & 0,03 & 2,94 & 0,06 & 0,925 \\
\hline Comunicação e atenção & 3,14 & 0,02 & 3,10 & 0,04 & 3,07 & 0,02 & 3,11 & 0,11 & 0,154 \\
\hline Humanização no atendimento & 3,22 & 0,03 & 3,13 & 0,04 & 3,08 & 0,02 & 3,17 & 0,12 & 0,001 \\
\hline Compreensão do cliente & 3,18 & 0,03 & 3,09 & 0,04 & 3,08 & 0,02 & 3,33 & 0,17 & 0,006 \\
\hline Prioridade nos interesses & 3,09 & 0,02 & 3,09 & 0,03 & 3,05 & 0,02 & 3,00 & 0,00 & 0,405 \\
\hline Acessibilidade dos clientes & 2,99 & 0,03 & 2,94 & 0,04 & 3,01 & 0,02 & 3,11 & 0,11 & 0,325 \\
\hline
\end{tabular}

Fonte: elaboração própria. 
Por fim, das análises das Tabelas 4 a 6, pode-se sintetizar que, na ampla maioria das 22 subdimensões de constructos, houve uma tendência de influência das variáveis mediadoras nível de atenção à saúde (18 subdimensões), nível de complexidade da assistência (15 subdimensões) e nível de escolaridade de usuários (14 subdimensões), na proxy J (506 informantes, visão de usuários).

Por sua vez, a análise das macrodimensões de qualidade estruturou-se a partir da valoração média atribuída aos constructos pelos indivíduos e calculadas para as macrodimensões propostas pelos informantes.

Pode-se sintetizar que houve diferença significativa quanto às variáveis nível de atenção à saúde, nível de complexidade da assistência e nível de escolaridade de usuários, para se considerar enquanto fatores mediadores em todas as macrodimensões de constructos (tangibilidade, confiabilidade, presteza, segurança e empatia), para a perspectiva de usuários, na proxy J. No entanto, quanto ao nível de complexidade essa tendência deve ser melhor investigada, por exemplo, com agregação de entrevistas em unidades de alta complexidade.

Diante desses resultados, a comprovação da tendência das variáveis nível de atenção à saúde, nível de complexidade da assistência e nível de escolaridade de usuários funcionarem enquanto fatores mediadores da ampla maioria das 22 subdimensões de constructos propostas, além de todas as cinco macrodimensões de qualidade originais da escala Servqual, trata-se de um achado inovador desta investigação.

Ressalte-se, ainda, que essa validação das cinco macrodimensões de qualidade, na perspectivas de usuários, na proxy J, estão alinhadas com a validação dessas mesmas macrodimensões originais da escala Servqual, nos estudos de Babakus e Mangold (1992) no contexto de saúde.

\section{Validação por usuários (análise inferencial)}

Concluídas as análises descritivas, em busca de validar, foi feita uma análise fatorial confirmatória (AFC) (HAIR et al., 2009) para as subdimensões de constructos, na proxy J ( $\mathrm{n}=506)$. Logo, pode-se destacar que, no modelo final, após análise e exclusão de dois constructos (CO15_apoio_U e CO19_prazo.atendim), todos os demais 38 constructos que permaneceram na análise, além da análise e exclusão de sete subdimensões de constructos (Confiança em prazos, confiabilidade organizacional, fornecimento de serviços, ocupação profissional, suprimento de recursos, compreensão do cliente e acessibilidade dos clientes), todas as 15 subdimensões de constructos apresentaram carga fatorial superior a 0,50 (ou suas permanências não impediram a validação convergente da AFC). 
Noutra análise, a qualidade e a validade das 22 subdimensões de constructos analisadas (equipamentos, estrutura física, apresentação pessoal, instalações físicas, confiança em prazos, etc) foi assegurada, uma vez que todas apresentaram validação convergente (AVE $>0,40$ ), confiabilidade adequada (A.C. $>0,60$ ou C.C. $>0,60$ ), unidimensionalidade e validação discriminante (VCM < AVE), na proxy J ( $n=506)$. Por sua vez, pode-se observar que a qualidade e a validade das cinco macrodimensões de qualidade percebida analisadas (tangibilidade, confiabilidade, presteza, segurança e empatia) foi assegurada, uma vez que todas apresentaram validação convergente (AVE $>0,40$ ), confiabilidade adequada (A.C. $>0,60$ ou C.C. $>0,60$ ), unidimensionalidade e validação discriminante (VCM < AVE), na proxy J $(n=506)$.

Para validar a variável latente qualidade global percebida foi feita uma análise fatorial confirmatória (AFC) (HAIR et al., 2009) da valoração média obtida para as macrodimensões de qualidade, na proxy J $(n=506)$. Logo, pode-se destacar que, no modelo final, após análise e exclusão de uma macrodimensão (tangibilidade), todas as demais quatro macrodimensões de qualidade que permaneceram na análise apresentaram carga fatorial superior a 0,50 (ou suas permanências não impediram a validação convergente da AFC), na proxy J.

Também se aplicaram testes para medir a qualidade (ajustamento) do modelo construído para as macrodimensões de qualidade percebida da proxy J (506 informantes), através de alguns índices selecionados na literatura relevante ( $X^{2} / G . L .$, CFI, TLI e RMSEA). Pode-se observar que os parâmetros e índices de ajustamento e qualidade dos modelos de equações estruturais indicaram bom ajuste, já que a razão entre a estatística qui-quadrado e os graus de liberdade foi menor que 3, as estatísticas TLI e o CFI foram maiores que 0,80 e o RMSEA foi menor que o limite máximo de 0,10.

Diante desses resultados, a Figura 3 sintetiza o ajuste da análise fatorial confirmatória (AFC) e a modelagem para a variável latente qualidade global percebida, na proxy J (506 informantes, visão de usuários). Devido ao elevado número de constructos, optou-se por omitir suas nomenclaturas, que ficaram identificados como $\mathrm{CO} 1$ a $\mathrm{CO} 40$. 
Figura 3 - Análise fatorial confirmatória da qualidade global percebida - proxy J (ciclo 2, estudo 4) (Visão de usuários).
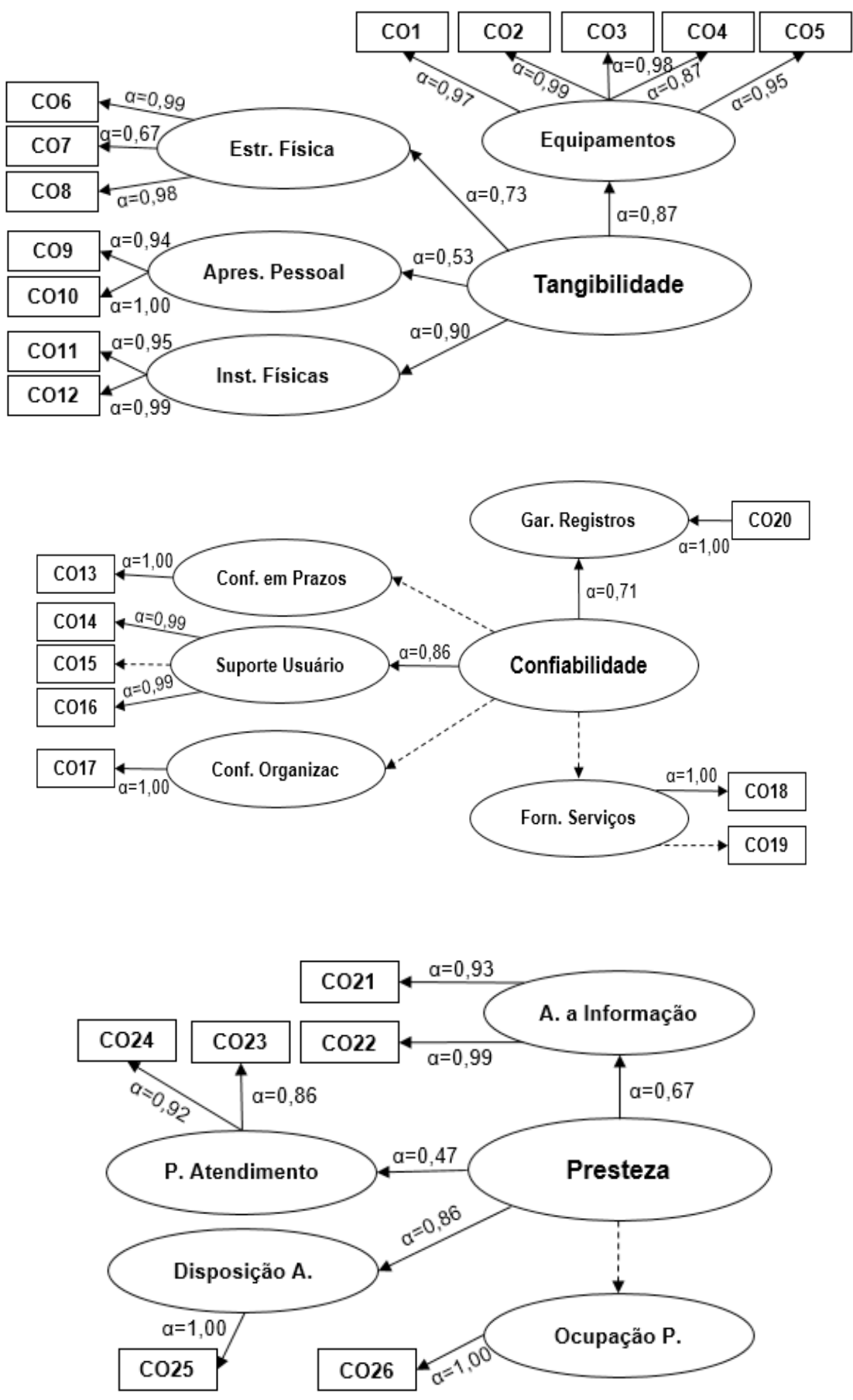

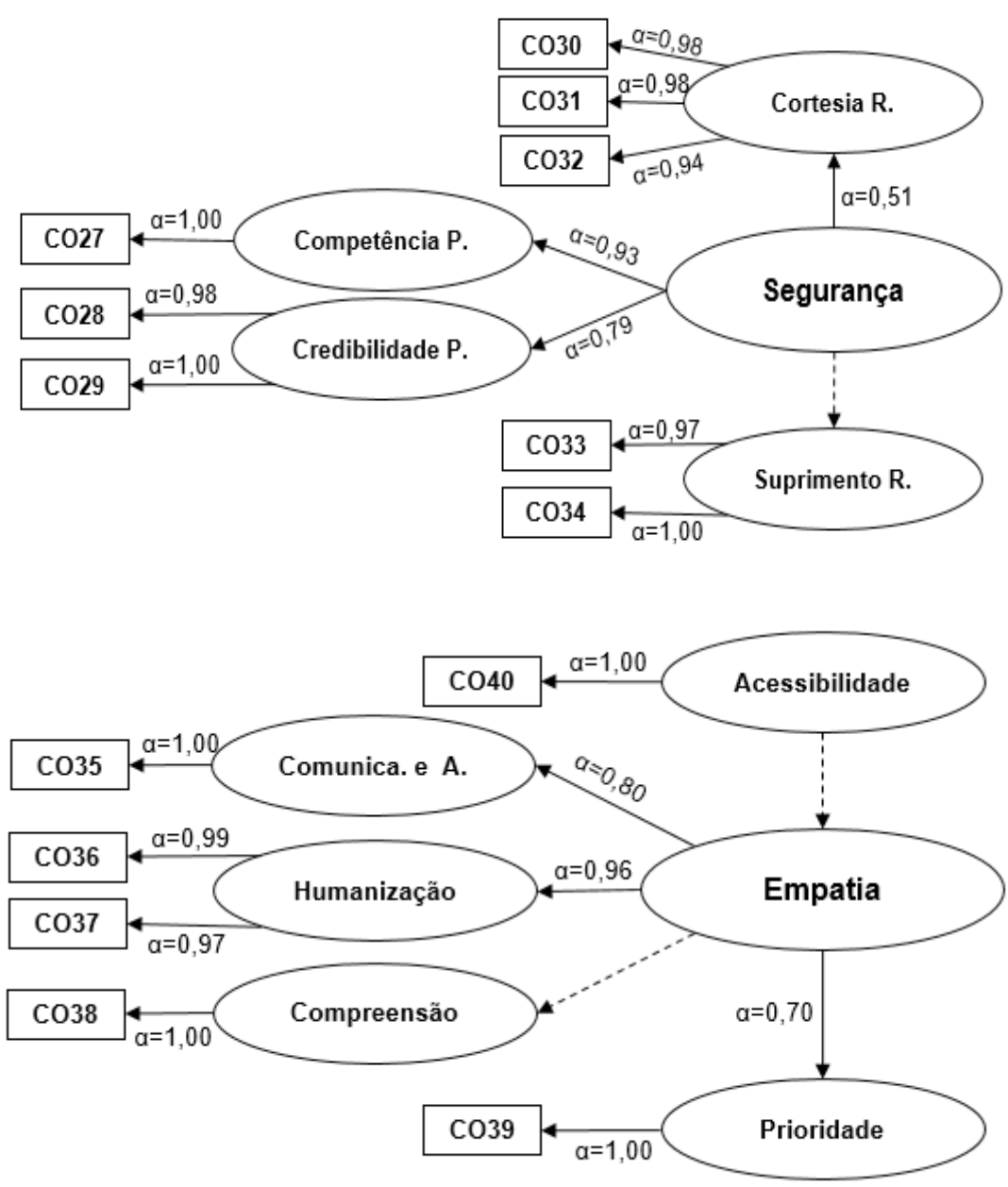

Fonte: elaboração própria.

Pode-se destacar que 38 dos 40 constructos propostos pelo painel de especialistas apresentaram cargas fatoriais validadas similares $(0,80$ a 1,00$)$ no modelo final, exceto os constructos CO15 e CO19. Em seguida a análise de carga fatorial, de subdimensões, eliminou sete das 22 subdimensões propostas (confiança em prazos, confiabilidade organizacional, fornecimento de serviços, ocupação profissional, suprimento de recursos, compreensão do paciente e acessibilidade). Nenhuma das subdimensões vinculadas às macrodimensões tangibilidade e segurança foram eliminadas no modelo final, revelando ampla concordância entre as propostas do painel de especialistas e as valorações dos grupos pilotos. Além disso, revelaramse distintos níveis de cargas fatoriais que podem se dividir em três grupos. Três subdimensões com cargas reduzidas (prioridade no atendimento - 0,47, cortesia nas relações - 0,51 e apresentação pessoal - 0,53), quatro com cargas medianas 
(acesso à informação - 0,68, prioridade no interesse dos clientes - 0,70, credibilidade profissional - 0,79 e comunicação e atenção - 0,80) e outras oito subdimensões com cargas elevadas (com carga maior que 0,85). Após análise e exclusão de uma macrodimensão (tangibilidade), todas as demais quatro macrodimensões de qualidade que permaneceram na análise apresentaram carga fatorial superior a 0,50 , ou seja, neste modelo final, garantiu-se a confiabilidade e a validade de 15 subdimensões e de quatro macrodimensões.

Para concluir a análise inferencial, foi possível observar que os constructos apresentaram maiores correlações com suas subdimensões de constructos, e as subdimensões apresentaram maiores correlações com suas respectivas macrodimensões de qualidade percebida, na proxy J $(n=506)$.

\section{Considerações finais}

No Brasil, na revisão da literatura não se constatou a existência de metodologia validada em uso para avaliar a satisfação dos usuários. Por sua vez, a iniciativa do Gespública (BRASIL, 2014) revela muita similaridade com as cinco dimensões e com as 22 questões da escala original Servqual (PARASURAMAN et al., 1991a; BerRY et al., 1994), mas, usada por meio de tradução livre, sem análises de confiabilidade e validade na construção da escala de satisfação que compõe o IPPS.

Os resultados obtidos das respostas de 195 profissionais e 506 usuários, em três fases sucessivas (painel de especialistas, grupos Delphi e pesquisa de campo), foram objetos de análise descritiva e de significância estatística. Os 40 constructos, as 22 subdimensões e as cinco macrodimensões que surgiram e tiveram valorações médias superiores ao nível relevante/importante (acima de 3) em todas as fases da pesquisa foram analisados, com rigor metodológico, sendo avaliados por análise inferencial apenas nos resultados dos usuários.

Da análise descritiva (Gráficos 1 a 3), pode-se sintetizar que houve validação dos itens de avaliação, propostos e analisados por grupos pilotos de especialistas e profissionais que atribuíram valoração média elevada (superior a 4, muito importante/relevante) para as subcategorias (40 constructos) às categorias (22 subdimensões de qualidade) e às macrocategorias (cinco macrodimensões de qualidade). Em seguida, a análise descritiva das respostas dos usuários (Gráfico 4 e Tabela 3) validou a ampla maioria dos itens de avaliação. De todos os 40 constructos originais propostos, a ampla maioria (18) das 22 subdimensões de constructos obteve valoração média, bem como todas as cinco macrodimensões de qualidade obtiveram valoração média elevada (superior a 3, importante/relevante), tendo sido considerados relevantes/importantes para aplicação da análise inferencial. 
Além disso, na ampla maioria das 22 subdimensões de constructos, houve uma tendência de influência das variáveis mediadoras nível de atenção à saúde (18 subdimensões), nível de complexidade da assistência (15 subdimensões) e nível de escolaridade de usuários (14 subdimensões), na proxy J. Noutra análise, houve diferença significativa quanto às variáveis nível de atenção à saúde, nível de complexidade da assistência e nível de escolaridade de usuários, para se considerar enquanto fatores mediadores em todas as macrodimensões de constructos (tangibilidade, confiabilidade, presteza, segurança e empatia), para a perspectiva de usuários, na proxy J (506 usuários). No entanto, quanto ao nível de complexidade essa tendência deve ser melhor investigada.

Concluídas as análises descritivas, aplicou-se uma análise fatorial confirmatória (AFC) (HAIR et al., 2009). A confiabilidade e a validade das 15 subdimensões e das cinco macrodimensões de constructos analisadas foram asseguradas. Para validar a variável latente qualidade global percebida foi feita uma análise fatorial confirmatória (AFC) (HAIR et al., 2009) que, após análise e exclusão de uma macrodimensão (tangibilidade), todas as demais quatro macrodimensões de qualidade (confiabilidade, presteza, segurança e empatia) foram validadas. Também se aplicaram testes para medir a qualidade (ajustamento) do modelo construído para as macrodimensões de qualidade percebida, através de alguns índices selecionados na literatura relevante (X²/G.L., CFI, TLI e RMSEA). Pode-se observar que os parâmetros e índices de ajustamento e qualidade dos modelos de equações estruturais indicaram bom ajuste. No modelo final, foram validados 38 constructos, 15 subdimensões e quatro macrodimensões de constructos, similares ao modelo Servqual (Figura 2).

Desses resultados das análises descritiva e fatorial demonstrou-se que há diferentes importâncias relativas atribuídas por especialistas, profissionais e usuários entre os constructos, subdimensões e macrodimensões de qualidade percebida e seus possíveis fatores mediadores, na mensuração de satisfação e qualidade percebida. A validação de quatro das cinco macrodimensões originais da escala Servqual demonstra que a nova escala proposta (Quality Saúde) mantevese globalmente alinhada com a escala estudada, mas a validação de apenas 15 das 22 subdimensões, propostas por uma amostra de especialistas e validadas por profissionais e usuários, trata-se de um processo inovador que estabeleceu subcategorias e categorias de dimensões analíticas passíveis de uso para comparação entre diferentes unidades avaliadas bem como enquanto itens de orientação para intervenção de gestores.

A validação da confiabilidade e da validade da ampla maioria dos itens de avaliação - 38 constructos (ideias-forças), 13 subdimensões e quatro macrodimensões de 
avaliação - enquanto mecanismo de mensuração da qualidade percebida pelos usuários subsidiará a construção de um novo instrumento, pela estruturação de um grupo de questões semiestruturadas, em um questionário aplicável aos usuários do SUS, já em planejamento para avanços da pesquisa, inclusive através do desenvolvimento de protótipo de uma plataforma de informática, usado como suporte tecnológico para aplicação do instrumento validado.

Outro resultado importante é a confirmação das diferenças significativas de fatores mediadores (níveis de atenção e de complexidade da assistência e nível de escolaridade dos usuários) nas valorações dos itens de avaliação (constructos, subdimensões e macrodimensões), que pode contribuir na compreensão de possíveis complexidades de aferição da qualidade e satisfação em saúde, que são consideradas de difícil mensuração na literatura (GRÖNROOS, 1990; ESPERIDIÃO ; TRAD, 2005; VINAGRE, 2008; ESPERIDIÃO, 2009). Sendo assim, podem-se estudar esses e outros fatores mediadores de valoração para explicar possíveis complexidades de mensuração.

Os resultados consolidados abrem novas perspectivas para a gestão dos serviços de saúde no sentido de se obter informações cientificamente válidas acerca da percepção dos usuários da saúde, possivelmente evitando as dificuldades e desalinhamentos de métodos de aferição sem validação por especialistas, e contribuindo para a mensuração da qualidade e satisfação do usuário por um método de seleção de itens de avaliação a partir das valorações de painéis de especialistas e grupos de profissionais. Também há o potencial de se impulsionar as pesquisas realizadas por algumas ouvidorias do SUS.

\section{Referências bibliográficas}

Aharony, L.; Strasser, S. Patient satisfaction: what we know about and what we still need to explore. Medical Care Review: Medical Care Review. v. 50, 31 p. 1993.

Albuquerque, J. D. Qualidade hospitalar: uma análise da sua realidade em Campina Grande - Paraíba - Brasil.. Doctoral Universidade de Extramadura, Espanha: Badajoz.2012.

BABAKUS; MANGOLD, G. Adapting Servqual Scale hospital service: na empirical investigation. Health Services Research: Health Services Research. 22. 1992.

BARBosA, L.; Neto, A. P. Ludwik Fleck (1896-1961) e translação do conhecimento: considerações sobre a genealogia de um conceito. Saúde Debate. Rio de Janeiro. v. 41, 13 p., 2017.

BATISTA, W. J.; PAIVA, A. D. A utilização do instrumento padrão de pesquisa de satisfação (IPPS) no diagnóstico de uma organização militar de saúde do exército brasileiro. XI Simpósio de Excelência em Gestão e Tecnologia- SEGeT. Resende - RJ 2014.

BERRY, L. L. et al. Improving service quality in America: lessons learned; executive commentary. The Academy of Management Executive, v. 8, n. 2, p. 21, 1994. 
Borges, J. B. C.; CARVAlho, S. M. R.; SILVA, M. A. M. Qualidade do serviço prestado aos pacientes de cirurgia cardíaca do Sistema Único de Saúde - SUS. Revista Brasileira de Cirurgia Cardiovascular. Marília, São Paulo - Brasil: Revista Brasileira de Cirurgia Cardiovascular. 252006.

Brasil. A saúde na opinião dos brasileiros. Ministério da Saúde. Brasília. 2003. Decreto $n^{\circ}$ 5.378, de 23 de fevereiro de 2005. Casa Civil, P. D. R. 2005. Programa Nacional de Gestão Pública e Desburocratização - Gespública. Manual de avaliação de satisfação do usuário do serviço público. Ministério do Planejamento, Orçamento e Gestão. Secretaria de Gestão Pública. Brasília. 2010 Governos estaduais no federalismo brasileiro. República, S. D. A. E. D. P. D. Brasilia: Instituto de Pesquisa Econômica Aplicada, 335 p. 2014.

CAMERON, K. Critical questions in assessing organizational effectiveness. Organization Dynamics. v. 6, 15 p. 1980.

Conselho Federal de Medicina (CFM). Pesquisa revela que 92\% da população está insatisfeita com a saúde no Brasil: Conselho Federal de Medicina Brasileiro. 2014.

. Para 93\% da população, a saúde no Brasil é considerada péssima, ruim ou regular: Conselho Federal de Medicina Brasileiro. 2015.

. Opinião dos brasileiros sobre o atendimento público na área de saúde 2018.

CHAHAL, H.; KUMARI, N. Consumer perceived value and consumer loyalty in the healthcare sector. Journal of Relationship Marketing, v. 10, n. 2, p. 15, 2011.

Consumer perceived value -The development of a multiple item scale in hospitals in the Indian context. International Journal of Pharmaceutical and Healthcare Marketing, v. 6, n. 2, p. 24, 2012.

CIHR, C. I. O. H. R. Knowledge translation strategy 2004-2009: innovation in action. CIHR. Ottawa. 2004.

ClaVier, C.; Sénéchal, Y.; PotviN, L. A theory - based model of translation practices in public health participatory research. Sociology of health and illness. Henley-onthames: Sociology of Health and Illness. v. 34, 16 p., 2011.

CONFEDERAÇÃo NACIONAL DA INDÚSTRIA (CNI), C. N. D. I.-. Retratados da sociedade brasileira: saúde publica (2011). CNI. Brasília. 2012.

Retratados da sociedade brasileira: saúde publica . CNI. Brasília. 2018.

CRONIN, J. R. J.; TAYLOR, A. S. Measuring service quality: a reexamination and a extension. American marketing association, v. 56, 1992.

Cruz, W. B. S.; Melleiro, M. M. Análise da satisfação dos usuários de um hospital privado. Revista Escola de Enfermagem da USP. São Paulo- Brasil: Revista da Escola de Enfermagem da USP, 2007.

Donabedian, A. The definition of quality: a conceptual exploration In: PRESS, $\mathrm{H}$. A. 1980 (Ed.). Explorations in Quality Assessment and Monitoring. Michigan, v.1, p. 30, 1980.

ESCOREL, S. et al. O Programa de Saúde da Família e a construção de um novo modelo para a atenção básica no Brasil. Rev. Panam. Salud Públ. /Pan Am. J. Public Health: 
Rev. Panam. Salud Públ. /Pan Am. J. Public Health. v. 21, 110 p., 2007.

EsPeridiÃo, M.; TRAD, L. A. B. Avaliação de satisfação de usuários. Ciência e saúde coletiva [online]: Ciência e saúde coletiva [online]. v. 10, 10 p., 2005.

ESPERIDIÃo, M. A. O usuário e o julgamento dos serviços de saúde. 171 Doctoral Universidade Federal da Bahia, Bahia. 2009.

Ferreira, J. J. et al. A model of entrepreneurial intention: an application of the psychological and behavioral approaches. Journal of Small Business and Enterprise Development, v. 19, p. 17, 2012.

FERreIRA, P. L. Family of instruments to evaluate hospital quality: a pilot test. Coimbra, Portugal: Faculty of Economics, 1993.

FERREIRA, P. L. et al. Determinantes da satisfação dos utentes dos cuidados primários: o caso de Lisboa e Vale do Tejo [Determinants of satisfaction of primary care users: the case of Lisbonand Tagus Valley]. Revista portuguesa de saúde pública, v. 2, p. 9, 2001.

FerreIRA, P. L.; Mendes, J. Hospital patient satisfaction: a Portuguese experience. European healthcare management association conference changing management in healthcare: new missions, conditions \& skills. EHMA, v. 69, 1997.

FERREIRA, P. L.; RAPOSO, V. M. A governação em saúde e a utilização de indicadores de satisfação [Health governance and the use of satisfaction indicators]. Revista Portuguesa de Clínica Geral: Revista Portuguesa de Clínica Geral. v. 22, 12 p., 2006.

FerreIRA, P. L.; RAPOSO, V. M.; PISCO, L. A voz dos utilizadores dos cuidados de saúde primários da região de Lisboa e Vale do Tejo, Portugal [The voice of primary care patients in the Lisbon and Tagus Valley region of Portugal]. Ciência \& Saúde Coletiva, v. 22, n. 3, p. 12, 2017.

GIESE, J. L.; COTE, J. A. Defining consumer satisfaction. Academy of Marketing Science Review, v.2000, p.24, 2000.Disponível em: < http://proquest.umi.com/pqdweb?did =344042051\&amp;amp;Fmt=7\&amp;amp; clientld=13656\&amp;amp;RQT=309\&a mp;amp;VName=PQD >.

GouveIA, G. C. et al. Satisfação dos usuários do sistema de saúde brasileiro: fatores associados e diferenças regionais. Rev. Bras. Epidemiol. v. 12, 15 p., 2009.

GrönRoos, C. Marketing edefined. Management Decision. v. 28, 1 p., 1990. Marketing: gerenciamento e serviços. Rio de Janeiro: Elsevier, 2003.

HaIR, J. F. et al. Análise multivariada de dados. 6a. Porto Alegre, 2009.

HARTZ, S.; JOHN, J. Contribution of economic evaluation to decision making in early phases of product development: A methodological and empirical review International journal of technology assessment in health care, v. 24, n. 4, p. 9, 2008. Hercos, B. V. S.; Brezovsky, A. Qualidade do serviço oftalmológico prestado aos pacientes ambulatoriais, do Sistema Único de Saúde - SUS. 15 Congresso NorteNordeste de Oftalmologia. Belo Horizonte, Minas Gerais - Brasil 2004.

MınAYo, M. C. S.; AssıS, S. G. D.; SouSA, E. R. Avaliação por triangulação de métodos - abordagem de programas sociais. Rio de Janeiro: Fundação Oswaldo Cruz, 2010. 
MoITA, G. F.; AL, E. Tradução, adaptação e validação cultural da escala Servqual para a mensuração de satisfação de usuários do SUS. In: 3을 CONGRESSO BRASILEIRO de POLÍTICA, PLANEJAMENTO E GESTÃo EM SAÚdE DA ABRASCO. Natal, 2017.

OLIVER, R. I. a Cognitive model of the antecedents and consequences of satisfaction decisions. Journal of Marketing Research, v. 17, n. 4, p. 10, 1980.

Measurement and evaluation of the satisfaction process in retail settings. Journal of Retailing, v. 57, n. 3, p. 24, 1981 a.

6 p. 1981 b.

What in costomer satisfaction? Wharton Magazine: Wharton Magazine. 5:

Parasuraman, A.; BerRy, L. L.; ZeithamL, V. A. A conceptual model of service quality and its implications for future research. Journal of Marketing, v. 49, p. 10, 1985a.

A conceptual model of service quality and its implications for future research. Journal of Marketing, v. 49, p. 41-50, 1985b.

Servqual: a multiple-item scale for measuring consumer perceptions of service quality. Joumal of Retailing, v. 64, p. 29, 1988.

Refinement and eassessment of the Servqual scale. Journal of Retailing, v. 67, n. 4, 1991a.

- Understanding costumer expectation of service. Sloan Management Review, v. 31, p. 10, $1991 \mathrm{~b}$.

PARAsuraman, A.; Zeithaml, V.; BerRy, L. Reassessment of expectations as a comparison standard in measuring service quality: implications for further research. Journal of Marketing, v. 58, p. 14, 1994.

Pedro, S.; FerreirA, P. L.; Mendes, J. Aplicação de métodos estatísticos na avaliação da satisfação dos utentes com o internamento hospitalar. Tourism \& Management Studies: Tourism \& Management Studies. v. 6, 15 p., 2010.

RoSAlEM, V. Análise das percepções dos principais atores da cadeia produtiva da saúde sobre a qualidade dos serviços prestados por hospitais no Estado de Goiás Brasil. 2013. Doctoral Escola de Administração de Empresas de São Paulo, São Paulo.

SAMPIERI, R. H.; Collado, C. F.; Lúcio, P. B. Metodologia de pesquisa. São Paulo: McGraw Hill, 2006.

SZYMANSKI, D. M.; HENARD, D. H. Customer satisfaction: a meta-analysis of the empirical evidence. Academy of Marketing Science. Journal, v. 29, n. 1, p. 1,2001 . Disponívelem:< http://proquest.umi.com/ pqdweb?did=65464878\&Fmt=7\&clientld=13656\&RQT=309\&VName=PQD >.

TSE, D. K.; WILTON, P. C. Models of consumer satisfaction: Na Extension. Journal of Marketing Research, v. 25, p. 9, 1988.

VINAGRE, M. H. A satisfação de utentes de serviços públicos de saúde: preditores e mediadores. Doctoral Instituto Superior de Ciências do Trabalho e da EmpresaISCTE, Portugal: Lisboa. 2008.

VOLPATO, L. F. Utilização de uma ferramenta para análise da qualidade nos serviços públicos de saúde. 112 Doctoral Faculdade de odontologia de Piracicaba, Universidade Estadual de Campinas, Piracicaba. 2014. 
VUORI, H. V. Quality assurance of health services: concepts and methodology. In: (Ed.). Public Health in Europe. Copenhagen: World Health Organization, Regional Office for Europe, v.16, 1982. p.127. ISBN 9289011521.

WHO, W. H. O. Bridging the "know-do" gap: meeting on knowledge translation in global health. WHO. Geneva. 2006.

YI, Y. A critical review of consumer satisfaction. In: ASSOCIATION, A. M. (Ed.). Review of Marketing. Chicago: American Marketing Association, 1990 p. 68-123.

\section{Galba Freire Moita}

Doutor em Gestão e Ciência da Decisão pela Universidade de Coimbra. Pesquisador-Especialista do Ministério da Saúde e da Fundação Osvaldo Cruz. Contato: prgalba@gmail.com

\section{Allan Claudius Queiroz Barbosa}

Doutor em Administração pela USP. Professor titular da FACE/UFMG e professor residente do IEAT/UFMG. Contato: allan@ufmg.br

\section{Vitor Manuel Reis Raposo}

Doutor em Gestão e Ciência da Decisão pela Universidade de Coimbra. Professor auxiliar da Faculdade de Economia da Universidade de Coimbra. Contato: vraposo@fe.uc.pt 


\section{Anexo}

\section{Tabela 7 - Pesquisa integrativa de definições conceptuais de satisfação de consumidores (usuários-utilizadores) - ordenamento cronológico}

\begin{tabular}{|c|c|c|c|c|}
\hline Fonte & Definição conceitual & Resposta & Enfoque & Tempo \\
\hline $\begin{array}{l}\text { (PLICHON, } 1999 \\
\text { citado por LICHTLÉ; } \\
\text { PLICHON, 2005) }\end{array}$ & $\begin{array}{l}\text { Estado afetivo proveniente dum } \\
\text { processo de avaliação afetivo } \\
\text { e cognitivo que advém de uma } \\
\text { transação específica }\end{array}$ & Estado afetivo & $\begin{array}{l}\text { Transação } \\
\text { específica }\end{array}$ & $\begin{array}{l}\text { Pós- } \\
\text { consumo }\end{array}$ \\
\hline $\begin{array}{l}\text { (AURIER; EVRARD, } \\
1988)\end{array}$ & $\begin{array}{l}\text { Um estado psicológico resultante } \\
\text { do processo de compra e de } \\
\text { consumo }\end{array}$ & $\begin{array}{l}\text { Estado } \\
\text { psicológico }\end{array}$ & $\begin{array}{l}\text { Processo de } \\
\text { compra e de } \\
\text { consumo }\end{array}$ & \\
\hline (OLIVER, 1997) & $\begin{array}{l}\text { Resposta de utilização dos } \\
\text { consumidores. É um julgamento } \\
\text { relativo que leva em consideração } \\
\text { tanto as qualidades (atributos) e } \\
\text { benefícios obtidos da aquisição, } \\
\text { como os custos e esforços do } \\
\text { consumidor para conseguir essa } \\
\text { aquisição }\end{array}$ & $\begin{array}{l}\text { Resposta/ } \\
\text { julga-mento de } \\
\text { realização }\end{array}$ & $\begin{array}{l}\text { Produto ou } \\
\text { serviço }\end{array}$ & $\begin{array}{l}\text { Durante } \\
\text { ou pós- } \\
\text { consumo }\end{array}$ \\
\hline (OLIVER, 1997) & $\begin{array}{l}\text { Um julgamento de que o serviço } \\
\text { forneceu um nível agradável de } \\
\text { realização relativa ao consumo }\end{array}$ & $\begin{array}{l}\text { Julgamento de } \\
\text { realização }\end{array}$ & Serviço & $\begin{array}{l}\text { Pós- } \\
\text { consumo }\end{array}$ \\
\hline $\begin{array}{l}\text { (OSTROM; } \\
\text { IACOBUCCI, 1995) }\end{array}$ & $\begin{array}{l}\text { A satisfação/insatisfação é um } \\
\text { julgamento relativo que leva em } \\
\text { consideração tanto as qualidades } \\
\text { (atributos) e os benefícios obtidos } \\
\text { da aquisição, como os custos e } \\
\text { esforços do consumidor para } \\
\text { conseguir essa aquisição. }\end{array}$ & $\begin{array}{l}\text { Julgamento } \\
\text { avaliativo } \\
\text { relativo }\end{array}$ & & \\
\hline $\begin{array}{l}\text { (HALSTEAD et al., } \\
\text { 1994) }\end{array}$ & $\begin{array}{l}\text { Uma resposta afetiva relativa } \\
\text { a uma transação específica } \\
\text { resultante da comparação entre } \\
\text { o desempenho do produto e } \\
\text { determinados padrões de compra } \\
\text { (idêntica a HUNT, 1977; OLIVER, } \\
\text { 1989) }\end{array}$ & Resposta afetiva & $\begin{array}{l}\text { Desempenho } \\
\text { por comparação } \\
\text { a padrões pré- } \\
\text { compra }\end{array}$ & $\begin{array}{l}\text { Durante o } \\
\text { consumo }\end{array}$ \\
\hline $\begin{array}{l}\text { (MANO; OLIVER, } \\
\text { 1993) }\end{array}$ & $\begin{array}{l}\text { Satisfação (com um produto) é } \\
\text { uma atitude idêntica ao julgamento } \\
\text { avaliativo pós-consumo (HUNT } \\
\text { 1977) que varia ao longo de um } \\
\text { contínuo hedônico (OLIVER, 1989; } \\
\text { WESTBROOK; OLIVER, 1991) }\end{array}$ & $\begin{array}{l}\text { Atitude - } \\
\text { julgamento } \\
\text { avaliativo } \\
\text { variando ao } \\
\text { longo de um } \\
\text { contínuo } \\
\text { hedônico }\end{array}$ & $\begin{array}{l}\text { Produto ou } \\
\text { serviço }\end{array}$ & $\begin{array}{l}\text { Pós- } \\
\text { consumo }\end{array}$ \\
\hline
\end{tabular}




\begin{tabular}{|c|c|c|c|c|}
\hline $\begin{array}{l}\text { (ANDERSON; } \\
\text { SULLIVAN, 1993) }\end{array}$ & $\begin{array}{l}\text { Uma avaliação pós-compra da } \\
\text { qualidade do produto a partir das } \\
\text { expectativas pré-compra }\end{array}$ & Avaliação & $\begin{array}{l}\text { Qualidade } \\
\text { do produto } \\
\text { Desconfirmação } \\
\text { às expectativas }\end{array}$ & Pós-compra \\
\hline (FORNELL, 1992) & $\begin{array}{l}\text { Uma avaliação global pós- } \\
\text { venda. Percepçãopós-compra } \\
\text { Desconfirmação entre o } \\
\text { desempenho do produto e as } \\
\text { expectativas }\end{array}$ & Avaliação global & $\begin{array}{l}\text { Desconfirmação } \\
\text { entre o desemp. } \\
\text { do produto e as } \\
\text { expectativas }\end{array}$ & $\begin{array}{l}\text { Pós- } \\
\text { consumo }\end{array}$ \\
\hline (OLIVER,1992) & $\begin{array}{l}\text { A satisfação é um somatório do } \\
\text { fenômeno atributivo com emoções } \\
\text { de consumo }\end{array}$ & $\begin{array}{l}\text { Fenômeno } \\
\text { atributivo + } \\
\text { emoções de } \\
\text { consumo }\end{array}$ & $\begin{array}{l}\text { Atributos do } \\
\text { produto }\end{array}$ & $\begin{array}{l}\text { Durante o } \\
\text { consumo }\end{array}$ \\
\hline $\begin{array}{l}\text { (WESTBROOK; } \\
\text { OLIVER, 1991) }\end{array}$ & $\begin{array}{l}\text { Julgamento avaliativo pós-escolha } \\
\text { referente a uma seleção específica }\end{array}$ & $\begin{array}{l}\text { Julgamento } \\
\text { avaliativo }\end{array}$ & $\begin{array}{l}\text { Seleção de } \\
\text { compra específica }\end{array}$ & Pós-escolha \\
\hline $\begin{array}{l}\text { (OLIVER; SWAN, } \\
1988)\end{array}$ & $\begin{array}{l}\text { Sem definição conceitual, mas uma } \\
\text { função da justiça e desconfirmação }\end{array}$ & & Vendedor & $\begin{array}{l}\text { Durante a } \\
\text { compra }\end{array}$ \\
\hline (TSE;WILTON, 1988) & $\begin{array}{l}\text { A resposta do consumidor } \\
\text { à avaliação da discrepância } \\
\text { percebida entre as expectativas } \\
\text { iniciais e o desempenho atual ou } \\
\text { percebido depois do consumo. }\end{array}$ & $\begin{array}{l}\text { Resposta a uma } \\
\text { avaliação }\end{array}$ & $\begin{array}{l}\text { Discrepância } \\
\text { percebida entre } \\
\text { as expectativas } \\
\text { prévias e o } \\
\text { desempenho }\end{array}$ & $\begin{array}{l}\text { Pós- } \\
\text { consumo }\end{array}$ \\
\hline $\begin{array}{l}\text { (CADOTTEet al., } \\
\text { 1987) }\end{array}$ & $\begin{array}{l}\text { Conceitualizada como uma } \\
\text { sensação desenvolvida através } \\
\text { da avaliação de experiência de } \\
\text { utilização. }\end{array}$ & $\begin{array}{l}\text { Sensação } \\
\text { desenvolvida } \\
\text { pela avaliação }\end{array}$ & $\begin{array}{l}\text { Experiência de } \\
\text { uso }\end{array}$ & $\begin{array}{l}\text { Durante o } \\
\text { consumo }\end{array}$ \\
\hline (WESTBROOK, 1987) & $\begin{array}{l}\text { Julgamento global avaliativo sobre } \\
\text { o consumo e uso do produto. }\end{array}$ & $\begin{array}{l}\text { Julgamento } \\
\text { global avaliativo }\end{array}$ & $\begin{array}{l}\text { Utilização } \\
\text { do produto/ } \\
\text { consumo }\end{array}$ & $\begin{array}{l}\text { Durante o } \\
\text { consumo }\end{array}$ \\
\hline (DAY, 1984) & $\begin{array}{l}\text { A resposta avaliativa a uma } \\
\text { experiência de consumo } \\
\text { relativamente à discrepância } \\
\text { percebida entre as expectativas } \\
\text { prévias e o desempenho percebido } \\
\text { (p.496). }\end{array}$ & $\begin{array}{l}\text { Resposta } \\
\text { avaliativa }\end{array}$ & $\begin{array}{l}\text { Discrepância } \\
\text { percebida entre } \\
\text { expectativas } \\
\text { prévias e } \\
\text { desempenho }\end{array}$ & Pós-compra \\
\hline $\begin{array}{l}\text { (BEARDEN; TEEL, } \\
\text { 1983) }\end{array}$ & $\begin{array}{l}\text { Sem definição conceitual, mas } \\
\text { uma função das expectativas } \\
\text { consideradas como crenças de } \\
\text { atributos dos produtos (já referido } \\
\text { por Olson e Dover, 1979) e da } \\
\text { desconfirmação (p. 22). }\end{array}$ & & & $\begin{array}{l}\text { Durante o } \\
\text { consumo }\end{array}$ \\
\hline $\begin{array}{l}\text { (LABARBERA; } \\
\text { MAZURSKY, 1983) }\end{array}$ & $\begin{array}{l}\text { Avaliação pós-compra: uma } \\
\text { avaliação da surpresa inerente } \\
\text { à aquisição de um produto ou à } \\
\text { experiência de consumo citando de } \\
\text { Oliver (1981), (p.394). }\end{array}$ & Avaliação & Surpresa & $\begin{array}{l}\text { Pós- } \\
\text { consumo ou } \\
\text { aquisição }\end{array}$ \\
\hline
\end{tabular}




\begin{tabular}{|c|c|c|c|c|}
\hline \multirow[t]{2}{*}{$\begin{array}{l}\text { (WESTBROOK; } \\
\text { REILLY, 1983) }\end{array}$} & $\begin{array}{l}\text { Uma resposta emocional a } \\
\text { experiências de consumo. }\end{array}$ & $\begin{array}{l}\text { Resposta } \\
\text { emocional }\end{array}$ & $\begin{array}{l}\text { Experiência de } \\
\text { consumo }\end{array}$ & Pós-compra \\
\hline & $\begin{array}{l}\text { Uma resposta emocional } \\
\text { despoletada por um processo } \\
\text { de avaliação cognitiva de } \\
\text { desconfirmação das percepções ou } \\
\text { crenças sobre o produto ou serviço } \\
\text { e os valores, necessidades ou } \\
\text { desejos do consumidor. }\end{array}$ & & $\begin{array}{l}\text { Percepções (ou } \\
\text { crenças) sobre } \\
\text { um objeto, ação } \\
\text { comparada } \\
\text { com valores } \\
\text { individuais }\end{array}$ & \\
\hline $\begin{array}{l}\text { (CHURCHILL; } \\
\text { SURPRENANT, 1982) }\end{array}$ & $\begin{array}{l}\text { Um resultado de compra e } \\
\text { utilização de um produto por } \\
\text { comparação com as recompensas e } \\
\text { custos da compra e consequências } \\
\text { antecipadas. Similar a atitude. }\end{array}$ & Resultado & $\begin{array}{l}\text { Comparação das } \\
\text { recompensas } \\
\text { e custos } \\
\text { relativamente às } \\
\text { consequências } \\
\text { antecipadas }\end{array}$ & $\begin{array}{l}\text { Pós- } \\
\text { consumo }\end{array}$ \\
\hline \multirow[t]{3}{*}{ (OLIVER, 1981A) } & $\begin{array}{l}\text { Uma avaliação da surpresa } \\
\text { inerente à aquisição de um produto } \\
\text { ou à experiência de consumo. }\end{array}$ & Avaliação & Surpresa & $\begin{array}{l}\text { Pós- } \\
\text { consumo ou } \\
\text { compra }\end{array}$ \\
\hline & & $\begin{array}{l}\text { Estado } \\
\text { psicológico }\end{array}$ & $\begin{array}{l}\text { Desconfirmação } \\
\text { de expectativas } \\
\text { em conjunto com } \\
\text { sensações prévias }\end{array}$ & \\
\hline & & Emoção & & \\
\hline \multirow[t]{2}{*}{$\begin{array}{l}\text { (SWAN; TRAWICK, } \\
\text { 1980) }\end{array}$} & $\begin{array}{l}\text { Avaliação consciente ou } \\
\text { julgamento cognitivo do } \\
\text { desempenho. A satisfação } \\
\text { envolve também afetos relativos a } \\
\text { sensações referentes aos produtos. }\end{array}$ & $\begin{array}{l}\text { Avaliação } \\
\text { consciente ou } \\
\text { julgamentos } \\
\text { cognitivos }\end{array}$ & $\begin{array}{l}\text { Através do } \\
\text { produto }\end{array}$ & $\begin{array}{l}\text { Durante } \\
\text { ou pós- } \\
\text { consumo }\end{array}$ \\
\hline & & $\begin{array}{l}\text { Dimensões } \\
\text { afetivas }\end{array}$ & & \\
\hline $\begin{array}{l}\text { (WESTBROOK, } \\
\text { 1980A) }\end{array}$ & $\begin{array}{l}\text { Refere-se à avaliação subjetiva } \\
\text { individual favorável dos resultados } \\
\text { e experiência de consumo } \\
\text { associada (citando Hunt, 1977). }\end{array}$ & $\begin{array}{l}\text { Avaliação } \\
\text { subjetiva } \\
\text { individual } \\
\text { favorável }\end{array}$ & $\begin{array}{l}\text { Resultados e } \\
\text { experiências }\end{array}$ & $\begin{array}{l}\text { Durante o } \\
\text { consumo }\end{array}$ \\
\hline (HUNT, 1977) & $\begin{array}{l}\text { Tipo de avaliação que considera } \\
\text { que a experiência é pelo menos tão } \\
\text { boa quanto deveria ser }\end{array}$ & $\begin{array}{l}\text { Avaliação da } \\
\text { experiência }\end{array}$ & $\begin{array}{l}\text { Experiência foi } \\
\text { pelo menos tão } \\
\text { boa quanto era } \\
\text { suposto ser }\end{array}$ & $\begin{array}{l}\text { Durante a } \\
\text { experiência } \\
\text { de consumo }\end{array}$ \\
\hline $\begin{array}{l}\text { (HOWARD; SHETH, } \\
\text { 1969) }\end{array}$ & $\begin{array}{l}\text { Estado cognitivo dos compradores } \\
\text { recompensados de forma } \\
\text { adequada ou desadequada em } \\
\text { função do seu sacrifício }\end{array}$ & Estado cognitivo & $\begin{array}{l}\text { Ser adequado ou } \\
\text { desadequado à } \\
\text { recompensa por } \\
\text { sacrifícios }\end{array}$ & \\
\hline
\end{tabular}




\begin{tabular}{|c|c|c|c|}
\hline (CARDOZO, 1965) & $\begin{array}{l}\text { Sem definição formal. Constatação } \\
\text { de que a satisfação deverá ser } \\
\text { um conceito mais global que a } \\
\text { simples avaliação de um produto, } \\
\text { envolvendo também toda a } \\
\text { experiência de consumo, através } \\
\text { da desconfirmação/confirmação de } \\
\text { expectativas e avaliação de esforço } \\
\text { dispendido (e outros elementos a } \\
\text { identificar em estudos posteriores) }\end{array}$ & $\begin{array}{l}\text { Avaliação } \\
\text { Desconfirmação/ } \\
\text { confirmação das } \\
\text { expectativas. } \\
\text { Avaliação } \\
\text { de esforço } \\
\text { dispendido }\end{array}$ & $\begin{array}{l}\text { Produto e } \\
\text { experiência de } \\
\text { consumo }\end{array}$ \\
\hline $\begin{array}{l}\text { Fonte: adaptado de } \\
\text { Giese e Cote ( } 2000 \\
\text { apud VINAGRE, } \\
2008, \text { p. } 23-25 \text { ) }\end{array}$ & & & \\
\hline & & & \\
\hline
\end{tabular}

Fonte: adaptado de Giese e Cote (2000 apud VINAGRE, 2008, p. 23-25) 